Contract No. and Disclaimer:

This manuscript has been authored by Savannah River Nuclear Solutions, LLC under Contract No. DE-AC09-08SR22470 with the U.S. Department of Energy. The United States Government retains and the publisher, by accepting this article for publication, acknowledges that the United States Government retains a non-exclusive, paid-up, irrevocable, worldwide license to publish or reproduce the published form of this work, or allow others to do so, for United States Government purposes. 


\title{
Energy efficiency limits for a recuperative bayonet sulfuric acid decomposition reactor for sulfur cycle thermochemical hydrogen production
}

\author{
Maximilian B. Gorensek* and Thomas B. Edwards \\ Computational Sciences Directorate, Savannah River National Laboratory, Aiken, SC 29808, \\ USA
}

A recuperative bayonet reactor design for the high-temperature sulfuric acid decomposition step in sulfur-based thermochemical hydrogen cycles was evaluated using pinch analysis in conjunction with statistical methods. The objective was to establish the minimum energy requirement. Taking hydrogen production via alkaline electrolysis with nuclear power as the benchmark, the acid decomposition step can consume no more than $450 \mathrm{~kJ} / \mathrm{mol} \mathrm{SO}_{2}$ for sulfur cycles to be competitive. The lowest value of the minimum heating target, $320.9 \mathrm{~kJ} / \mathrm{mol} \mathrm{SO}_{2}$, was found at the highest pressure $(90 \mathrm{bar})$ and peak process temperature $\left(900^{\circ} \mathrm{C}\right)$ considered, and at a feed concentration of $42.5 \mathrm{~mol} \% \mathrm{H}_{2} \mathrm{SO}_{4}$. This should be low enough for a practical watersplitting process, even including the additional energy required to concentrate the acid feed. Lower temperatures consistently gave higher minimum heating targets. The lowest peak process temperature that could meet the $450-\mathrm{kJ} / \mathrm{mol} \mathrm{SO}_{2}$ benchmark was $750^{\circ} \mathrm{C}$. If the decomposition reactor were to be heated indirectly by an advanced gas-cooled reactor heat source $\left(50^{\circ} \mathrm{C}\right.$ temperature difference between primary and secondary coolants, $25^{\circ} \mathrm{C}$ minimum temperature difference between the secondary coolant and the process), then sulfur cycles using this concept could be competitive with alkaline electrolysis provided the primary heat source temperature is at least $825^{\circ} \mathrm{C}$. The bayonet design will not be practical if the (primary heat source) reactor outlet temperature is below $825^{\circ} \mathrm{C}$.

\footnotetext{
* To whom correspondence should be addressed. E-mail: maximilian.gorensek@srnl.doe.gov. Tel.: (803) 725-1314. Fax: (803) 725-8829.
} 


\section{Introduction}

The total quantity of hydrogen produced worldwide in 2004 was estimated to be 50 million metric tons, of which some $95 \%$ was captive. ${ }^{1}$ That means only about 2.5 million metric tons were available for sale on the merchant market. The National Academies estimate that by 2050 the demand for hydrogen as a transportation fuel in the United States alone will be about 100 million metric tons per year if all gasoline light-duty vehicles are replaced with hydrogen vehicles, ${ }^{2}$ about forty times the current worldwide merchant market. Clearly, hydrogen will be practical as a transportation fuel only if it can be efficiently generated on a massive scale.

Thermochemical cycles have been proposed as a means for making massive quantities of hydrogen by using heat from a nuclear reactor to split water. The National Academies found that thermochemical cycles, particularly sulfur cycles, offer the possibility of more efficient hydrogen production without any $\mathrm{CO}_{2}$ emissions. ${ }^{2}$ The two sulfur cycles that have received the most attention are the sulfur-iodine (SI) ${ }^{3}$ and the hybrid sulfur (HyS). ${ }^{4}$

The SI, HyS, and other sulfur cycles share a common step, the high-temperature decomposition of sulfuric acid,

$$
\mathrm{H}_{2} \mathrm{SO}_{4}(a q) \stackrel{\text { Heat, } \mathrm{T}>800^{\circ} \mathrm{C}}{\longrightarrow} \mathrm{H}_{2} \mathrm{O}(g)+\mathrm{SO}_{2}(g)+\frac{1}{2} \mathrm{O}_{2}(g) \text {. }
$$

This reaction requires a catalyst as well as heat input at high temperatures in order to achieve equilibrium conversion. ${ }^{5}$ It also entails boiling (i.e. vaporizing liquid) sulfuric acid at concentrations and temperatures that make it highly corrosive to most conventional materials of construction.

Silicon carbide $(\mathrm{SiC})$ is one material that has been shown to be capable of withstanding the conditions under which high-temperature sulfuric acid decomposition occurs. However, since it is a ceramic, $\mathrm{SiC}$ is not as easily shaped as typical metals. More importantly, making 
connections and maintaining seals between $\mathrm{SiC}$ and/or $\mathrm{SiC}$-metal components at the temperatures and pressures required for decomposing sulfuric acid is challenging.

Researchers at Sandia National Laboratories (SNL) have designed a recuperative bayonet sulfuric acid decomposition reactor that features all-SiC construction for the heated parts, can be made from readily available $\mathrm{SiC}$ shapes, makes the most use of heat recuperation, and has all of its fluid connections at sufficiently low temperatures so that conventional seal materials can be used. Bench-scale experiments using electric resistance heaters as the energy source have verified that the design functions as intended. ${ }^{6}$

The purpose of this work was to apply a pinch analysis to the SNL design to establish the limiting performance (heating target) as a function of operating conditions. This needed to be determined before any significant development effort was invested. If the minimum value of the heating target had been found to be too high to achieve satisfactory thermal efficiency, then further development of the bayonet design would have been unwarranted. Mapping out the limiting performance also helped ascertain the practical operating range, allowing the reactor to be integrated into a conceptual flowsheet. Of particular interest was the effect of temperature, which will be limited by the operating temperature of the nuclear reactor heat source and is an important variable.

\section{Background}

2.1. Energy Considerations. As noted elsewhere, nuclear heat-driven thermochemical cycles will inevitably be benchmarked against alkaline electrolysis (of water) coupled with conventional nuclear power generation. ${ }^{7}$ The latter makes use of proven technology and could be deployed almost immediately. Water-splitting via electrolysis is conceptually simpler than any thermochemical cycle and, therefore, likely to require a smaller capital investment. 
Consequently, thermochemical cycles will need to have higher net thermal efficiencies than alkaline electrolysis using nuclear power in order to be competitive. Higher net thermal efficiency means fewer or smaller nuclear reactor heat sources are needed to make the same quantity of hydrogen. Since the nuclear heat source should be the most capital-intensive component, the nuclear-thermochemical plant would then have the lower total capital investment, resulting in a lower hydrogen production cost.

Pressurized alkaline electrolyzers make hydrogen at a $68 \%$ electric-to-hydrogen lower heating value (LHV) conversion efficiency. (The LHV for hydrogen is $242 \mathrm{~kJ} / \mathrm{mol}^{7}$ ) If the primary energy source is a conventional boiling water reactor (BWR) or pressurized water reactor (PWR) steam Rankine cycle power plant, the thermal-to-electric conversion efficiency is approximately $33 \%$. This would give an overall conversion efficiency for conventional alkaline electrolysis of $22.4 \%$ (LHV basis), resulting in a primary energy requirement of $1080 \mathrm{~kJ} / \mathrm{mol} \mathrm{H}_{2}$. High-temperature gas-cooled reactor (HTGR) helium closed loop Brayton cycle power plants are projected to operate with 42 to $48 \%$ conversion efficiency, depending on reactor outlet temperature. ${ }^{7}$ Choosing $45 \%$ as a representative value, pressurized alkaline electrolyzers coupled to an HTGR power plant could produce hydrogen at $30.6 \%$ efficiency, LHV basis, equivalent to a primary energy requirement of $791 \mathrm{~kJ} / \mathrm{mol} \mathrm{H}_{2}$ product. Thus, alkaline electrolysis has a primary energy requirement of 800 to $1100 \mathrm{~kJ} / \mathrm{mol} \mathrm{H}$, depending on the efficiency of the power source.

Taking into account the energy needs of the rest of the cycle (primarily $\mathrm{SO}_{2}$-depolarized electrolysis), HyS can surpass this efficiency benchmark provided the energy required for the high-temperature decomposition of sulfuric acid does not exceed $450 \mathrm{~kJ} / \mathrm{mol} \mathrm{SO}_{2}$ product. $^{7}$ Similar limitations apply for sulfuric acid decomposition in the SI cycle. An efficiency analysis identified three different flowsheets for high-temperature sulfuric acid decomposition in the SI 
cycle that had energy requirements between 389 and $441.5 \mathrm{~kJ} / \mathrm{mol} \mathrm{SO}_{2},{ }^{8}$ while a fourth sulfuric acid decomposition flowsheet has been proposed for the SI cycle that requires only $373 \mathrm{~kJ} / \mathrm{mol}$ $\mathrm{SO}_{2}$ product. ${ }^{9}$ This leads to the conclusion that the heating target needs to be less than 450 $\mathrm{kJ} / \mathrm{mol} \mathrm{SO}_{2}$ in order for the bayonet design to be a feasible option for the sulfuric acid decomposition step in a sulfur cycle.

2.2. Bayonet Decomposition Reactor Design. Sulfuric acid decomposes in two sequential, equilibrium-limited steps. As liquid acid is vaporized and superheated, it spontaneously dissociates into water and sulfur trioxide vapor, $\mathrm{SO}_{3}(g)$,

$$
\mathrm{H}_{2} \mathrm{SO}_{4}(a q) \stackrel{\text { Heat, } \mathrm{T}>300^{\circ} \mathrm{C}}{\longrightarrow} \mathrm{H}_{2} \mathrm{O}(g)+\mathrm{SO}_{3}(g) . \quad\left(\mathrm{R}_{1 \mathrm{a}}\right)
$$

The extent of dissociation increases with temperature. Further heating the vapor in the presence of a suitable catalyst and at sufficiently high temperatures $\left(>800^{\circ} \mathrm{C}, 1073 \mathrm{~K}\right)$ causes endothermic decomposition of the $\mathrm{SO}_{3}$,

$$
\mathrm{SO}_{3}(g) \stackrel{\text { Heat, } \mathrm{T}>800^{\circ} \mathrm{C}}{\longrightarrow} \mathrm{SO}_{2}(g)+\frac{1}{2} \mathrm{O}_{2}(g)
$$

The net result of these two reactions is Reaction $R_{1}$.

The bayonet decomposition reactor is designed to take a liquid sulfuric acid feed at moderate temperature (ca. $100^{\circ} \mathrm{C}, 373 \mathrm{~K}$ ) and preheat, vaporize, superheat, and decompose it inside a $\mathrm{SiC}$ tube with one end closed, using high-temperature heat from an advanced nuclear reactor like the proposed Next Generation Nuclear Plant (NGNP). ${ }^{10}$ Heat is also recovered from the hot vapor product by heat exchange, resulting in a partially condensed product stream at a sufficiently low temperature $\left(\leq 250^{\circ} \mathrm{C}, 523 \mathrm{~K}\right)$ to allow the use of conventional seal materials. A schematic of this concept is shown in Figure 1. 


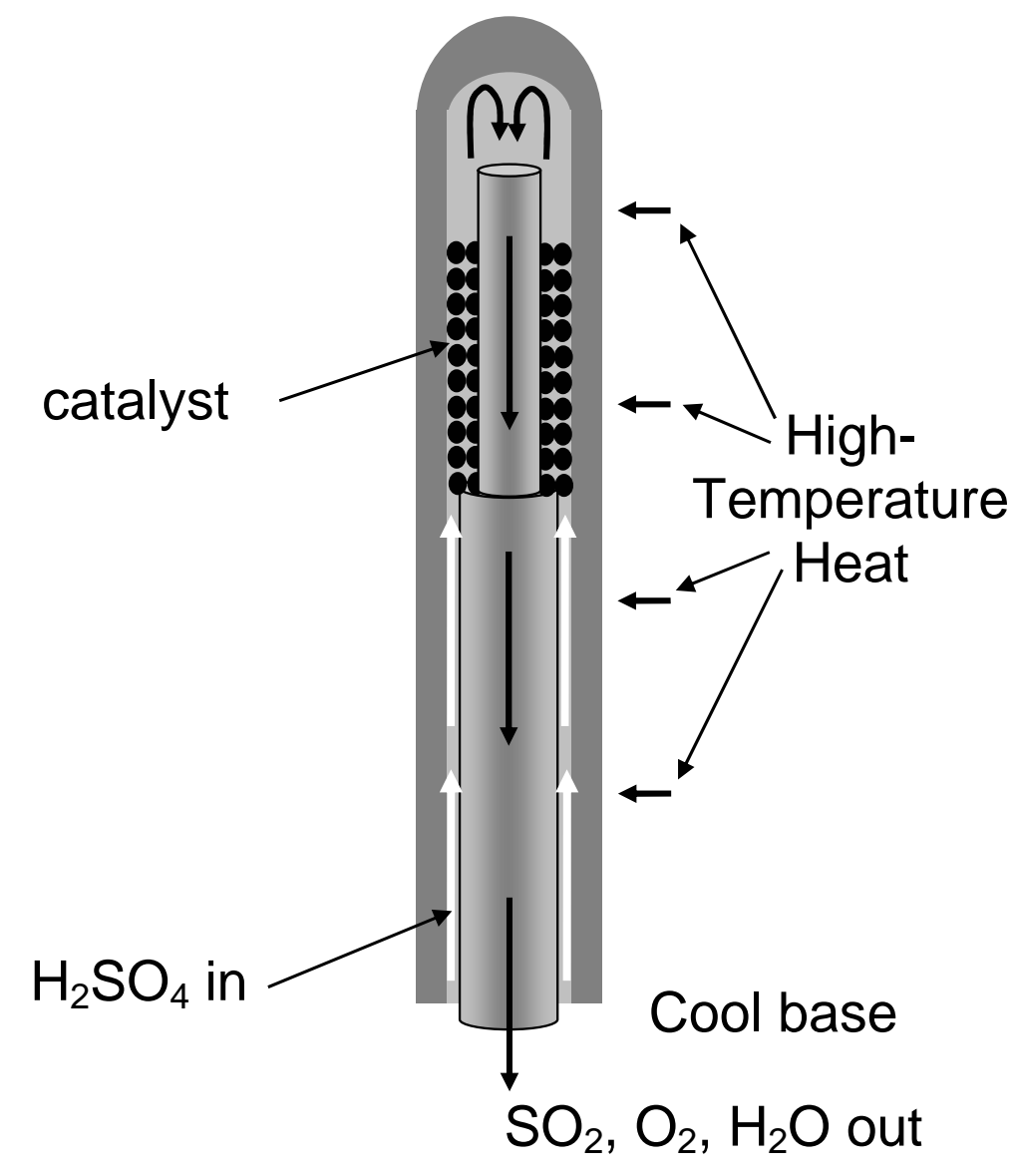

Figure 1. High-temperature bayonet reactor concept for sulfuric acid decomposition. ${ }^{7}$

The most likely heat transfer medium will be helium gas at 800 to $900^{\circ} \mathrm{C}$ (1073 to 1173 K) and 60 to 90 bar pressure. Heat will be available over a 300- to 500-degree range, depending on the return temperature to the nuclear heat source $\left(350\right.$ to $550^{\circ} \mathrm{C}, 623$ to $\left.823 \mathrm{~K}\right)$. Since helium is a monatomic, nearly ideal gas, the heat capacity of the reactor coolant will be essentially constant over its entire temperature range. Consequently, heat from the nuclear energy source will be evenly distributed over its temperature range. A simplified drawing of what a commercial scale high-temperature decomposition reactor based on the bayonet concept might look like is shown in Figure 2. ${ }^{11}$ More information on the bayonet decomposition reactor concept is available elsewhere. ${ }^{7,12}$ 


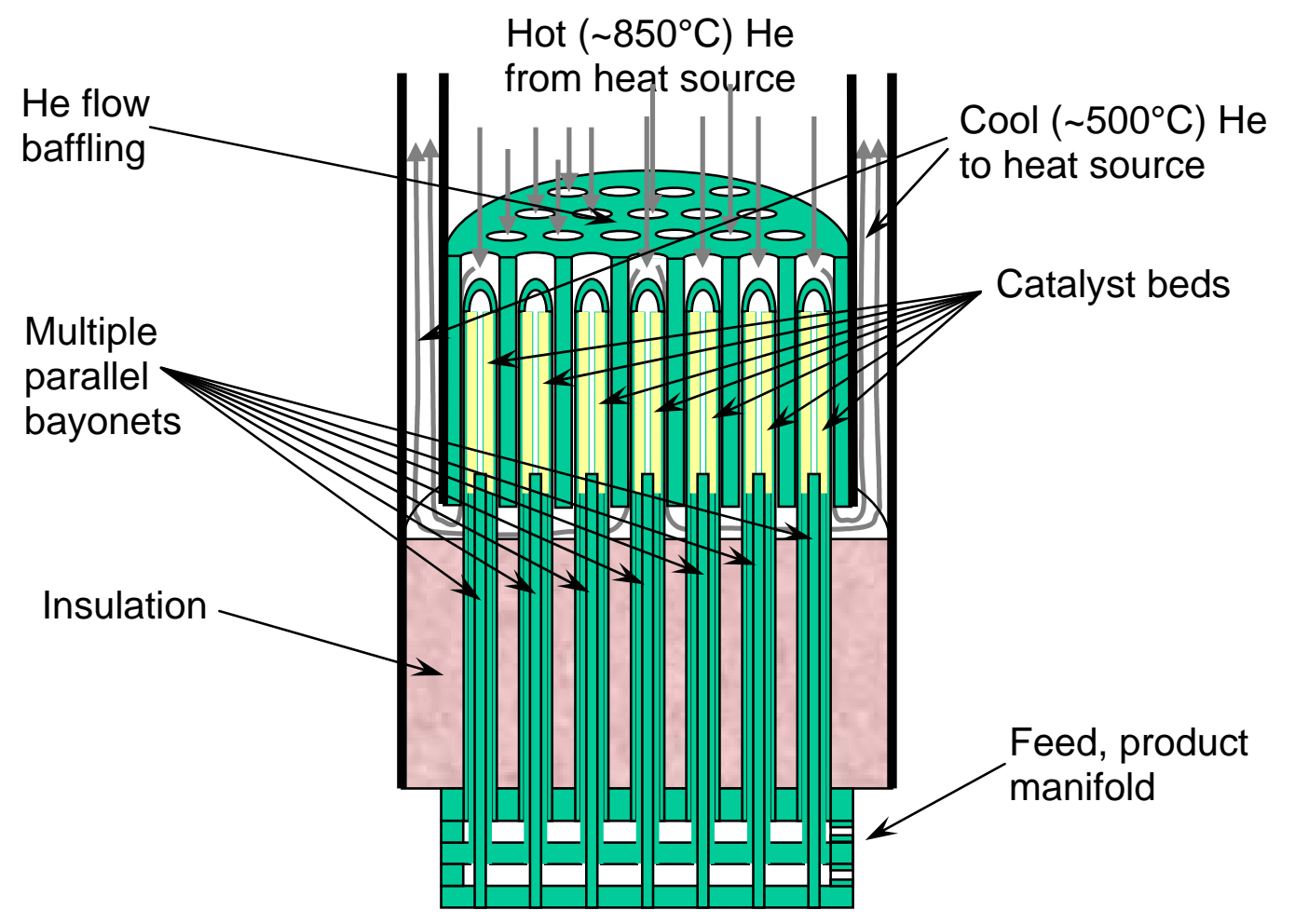

Figure 2. Simplified schematic of a production scale high-temperature bayonet reactor for sulfuric acid decomposition.

\section{Analysis}

3.1. Simulation Model. A detailed description of the Aspen Plus Version $7.0^{13}$ simulation model used to determine the heating target for the bayonet reactor is available elsewhere. ${ }^{7}$ The model tracks the sulfuric acid process fluid as it passes through the reactor, making several key assumptions: 1) operation is steady-state, 2) fluid moves through the reactor in plug (single-phase) or homogeneous (two-phase) flow, 3) the cross-section of the flow path is well-mixed, and 4) local thermodynamic and phase equilibrium is maintained throughout. In reality, there may well be localized disengagement between phases in the boiling and condensing regions as well as radial gradients. However, the width of the flow channel is much smaller than the length (by at least two orders of magnitude), and steady-state operation eliminates the 
possibility of changes in the average composition along the flow path other than those caused by reactions $\left(\mathrm{R}_{1 \mathrm{a}}\right)$ and $\left(\mathrm{R}_{1 \mathrm{~b}}\right)$. Consequently, these differences should not lead to significant departures of the predicted from the actual heating and cooling behavior of the process fluid.

The model simulates heating the sulfuric acid in small temperature increments, maintaining phase and dissociation reaction $\left(\mathrm{R}_{1 \mathrm{a}}\right)$ equilibrium, and calculating the enthalpy change for each increment. This continues as the liquid boils and vaporizes, and the vapor is superheated. When the vapor reaches the catalyst bed inlet temperature, equilibrium with respect to the $\mathrm{SO}_{3}$ decomposition reaction $\left(\mathrm{R}_{1 \mathrm{~b}}\right)$ is imposed as well, and the fluid is further heated in small temperature increments, with changes in enthalpy being tracked. Once the peak process fluid temperature is achieved, which indicates that the fluid has reached the catalyst bed outlet, Reaction $\mathrm{R}_{1 b}$ is turned off. The vapor bed effluent is then cooled in small temperature decrements, the phase and Reaction $\mathrm{R}_{1 \mathrm{a}}$ equilibrium is maintained, and the enthalpy change for each decrement is calculated until the original inlet temperature is achieved and the product is partially condensed.

Six process variables were considered by the simulation model. They included the temperature, $T_{i}\left({ }^{\circ} \mathrm{C}\right.$ ), pressure, $P_{i}$ (bar), and acid concentration, $x_{i}$ (expressed as $\mathrm{SO}_{3}$ mole fraction) of the feed; the process fluid temperatures $\left({ }^{\circ} \mathrm{C}\right)$ at the inlet, $T_{c a t}$, and the outlet, $T_{\max }$, of the catalyst bed; and the temperature approach to equilibrium, $\Delta T_{e q}\left({ }^{\circ} \mathrm{C}\right)$, of the decomposition reaction in the catalyst bed. The ability to specify pressure drop values for five distinct zones (liquid preheating and boiling, vapor superheating, catalyst bed, vapor cooling, and partial condensing) was also incorporated into the model, although the inclusion of pressure drops was found not to have a material effect on the outcome. Consequently, unless otherwise noted, the reactor was assumed to operate at constant pressure. 
Heating and cooling curves for the sulfuric acid process fluid can be constructed from the model results by plotting the temperature on the ordinate and relative enthalpy on the abscissa. Two separate curves are drawn for fluid being heated (from cold bayonet feed to catalyst bed outlet) and cooled (from hot catalyst bed outlet to partially condensed bayonet product). This provides the raw data needed for a pinch analysis of the reactor.

3.2. Pinch Analysis. Aspen Energy Analyzer Version $7.0^{14}$ software was used to determine the heating and cooling targets from the heating and cooling curves generated by the Aspen Plus model. The heating target, $Q_{H, \min }$, represents the minimum amount of hightemperature heat that would be needed to carry out the sulfuric acid decomposition reaction assuming full utilization of the heat available for recuperation, $Q_{R, \max }$. The cooling target, $Q_{C, \text { min }}$, gives a lower bound on the amount of low grade heat that can be rejected by the bayonet reactor effluent.

The analysis presented here does not include a detailed heat transfer design, since it is intended to be a bounding calculation. It is sufficient to assume that the bayonet design (e.g. heat exchange area, heat transfer coefficients, etc.) is adequate for the heat transfer needed. Consequently, assuming that the heat exchange and reaction can be accomplished with a practical bayonet length and with reasonable temperature differences between the hot and cold sides, this calculation establishes the lowest possible energy input needed by the bayonet reactor.

Figure 3 shows a representative example of the heating and cooling curves generated by Aspen Energy Analyzer from the Aspen Plus simulation results. In this instance, the minimum temperature difference for recuperative heat exchange, $\Delta T_{\text {min,recup }}$, was assumed to be $10^{\circ} \mathrm{C}$. $\Delta T_{\text {min,recup }}$ is the seventh process variable and is determined by the bayonet heat transfer design. The lower, blue curve represents the temperature of the reacting mixture in the annulus as a 
function of the cumulative amount of heat added, while the upper, red curve can be thought of as the temperature of the reaction product in the center tube as a function of the amount of heat yet to be removed. Since the fluid in the annulus is being continually heated, while the fluid in the center tube is continually cooled, and the two flows are countercurrent, the enthalpy maps monotonically to axial displacement from the open end of the bayonet. The point of closest approach, where the curves are separated by only $10^{\circ} \mathrm{C}$, is called the pinch point. For the conditions in Figure 3, the pinch occurs at $506.5^{\circ} \mathrm{C}$ on the feed side (in the boiling region) and $516.5^{\circ} \mathrm{C}$ on the product side (near the onset of condensation).

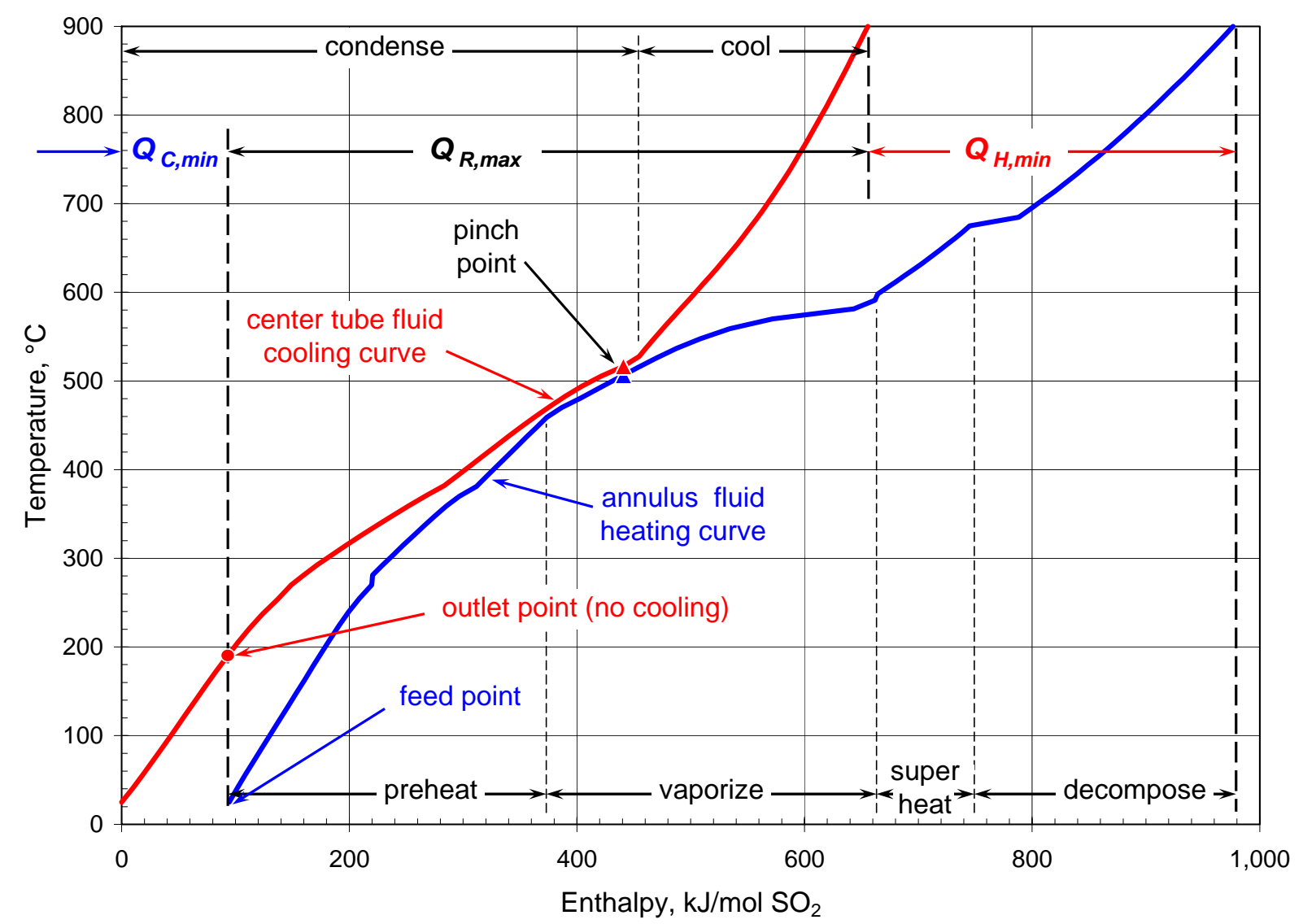

Figure 3. Heating and cooling curves for bayonet decompositon reactor: $29.8 \mathrm{~mol} \% \mathrm{SO}_{3}$ feed at $25^{\circ} \mathrm{C}$ and 90 bar; $675^{\circ} \mathrm{C}$ and $900^{\circ} \mathrm{C}$ catalyst bed inlet and outlet temperatures, respectively; $0^{\circ} \mathrm{C}$ temperature approach to decomposition equilibrium; $10^{\circ} \mathrm{C}$ minimum temperature difference. 
The minimum heating target, $Q_{H, \min }$, for the conditions in Figure 3 is $320.9 \mathrm{~kJ} / \mathrm{mol} \mathrm{SO}_{2}$. This means that the amount of high-temperature heat needed to drive the decomposition reactor at Figure 3 conditions is at least equal to $320.9 \mathrm{~kJ} / \mathrm{mol} \mathrm{SO}_{2}$ (for a perfectly matched heat transfer design). If the design of the bayonet does not match the heat transfer requirements, so that crosspinch heat exchange occurs, then the heat requirement will be greater than $Q_{H, \text { min }}$.

Another useful item of information is the temperature range over which the hightemperature heat source can be efficiently applied. This was established by using Aspen Energy Analyzer to perform a utility pinch analysis as shown in Figure 4.

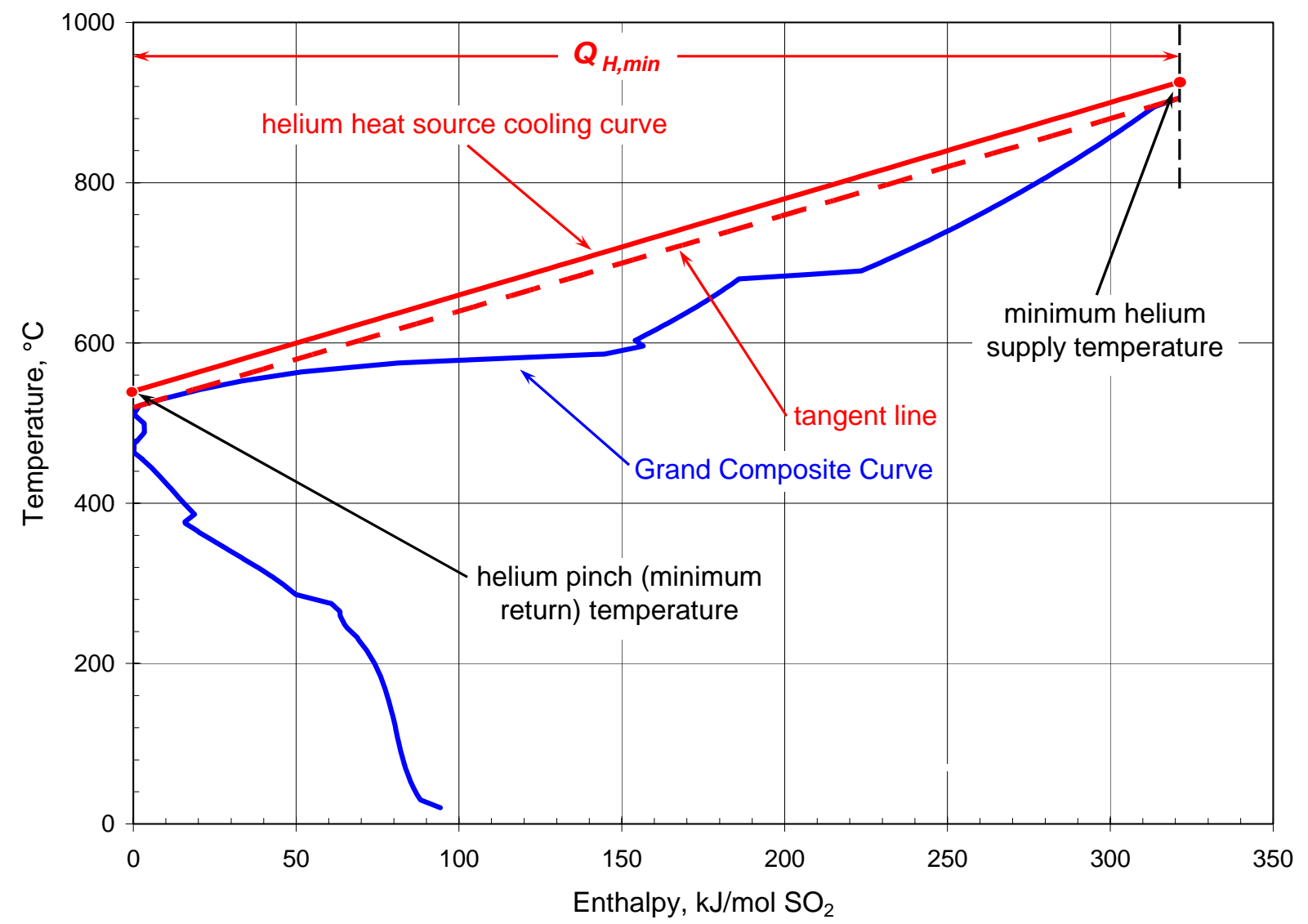

Figure 4. Utility pinch analysis for bayonet decompositon reactor: $29.8 \mathrm{~mol} \% \mathrm{SO}_{3}$ feed at $25^{\circ} \mathrm{C}$ and 90 bar; $675^{\circ} \mathrm{C}$ and $900^{\circ} \mathrm{C}$ catalyst bed inlet and outlet temperatures, respectively; $0^{\circ} \mathrm{C}$ temperature approach to decomposition equilibrium; $10^{\circ} \mathrm{C}$ internal (recuperative), $25^{\circ} \mathrm{C}$ external (helium-to-process fluid) minimum temperature difference. 
The blue line in Figure 4 is the grand composite curve (GCC), which can be thought of as a "net process cold stream" above the pinch temperature, and a "net process hot stream" below. ${ }^{15}$ Since the heat capacity of the helium coolant heat source is nearly independent of temperature, its cooling curve in Figure 4 is a straight line. Consequently, the temperature range over which high-temperature heat from the nuclear heat source can be used is easily determined by drawing a tangent line to the GCC, above its pinch point. The solid red line stretching between the abscissa values of $Q_{H, \min }$ and zero represents the helium cooling curve with the lowest possible initial and final temperatures for efficient operation (without cross-pinch heat transfer). It is obtained by shifting the (broken red) tangent line upward by a value of $\Delta T_{\min , H e}-1 / 2 \Delta T_{\min , \text { recup }}$, where $\Delta T_{\min , \mathrm{He}}$ is the minimum temperature difference for helium-to-process fluid heat transfer. (The $1 / 2 \Delta T_{\text {min,recup }}$ correction is necessary because the GCC plots interval boundary temperatures instead of stream temperatures, which are shifted $1 / 2 \Delta T_{\text {min, recup }}$ above cold stream temperatures and $1 / 2 \Delta T_{\text {min, recup }}$ below hot stream temperatures. ${ }^{15}$ ) For the conditions in Figure 4 , the minimum helium supply temperature is $925^{\circ} \mathrm{C}$ (one tangent point is at the highest process fluid temperature, $900^{\circ} \mathrm{C}$ ), while the helium pinch (minimum return) temperature is $539.7^{\circ} \mathrm{C}$.

In the absence of cooling, the minimum process outlet temperature of the bayonet reactor product will be equal to that temperature at which the enthalpy of the cooling curve matches the enthalpy of the heating curve at the inlet temperature. (See Figure 3.) In this case, the minimum process outlet temperature is $192.4^{\circ} \mathrm{C}$. Thus, for a perfectly matched bayonet design, $192.4^{\circ} \mathrm{C}$ should be the outlet temperature at Figure 3 conditions. If, however, the heat input is greater than $Q_{H, \min }$ (i.e. the design of the bayonet does not match the heat transfer requirements), the outlet temperature will be correspondingly higher. 
Pinch analysis can be used in this manner to establish the limiting performance of the bayonet decomposition reactor at any set of operating conditions without having to do a rigorous heat transfer analysis. Once the practical operating envelope is mapped out, the results of the analysis for a particular set of operating conditions can be substituted into a flowsheet model to determine the limiting performance of the flowsheet.

Initial simulations and pinch analyses of the bayonet reactor gave some unexpected results. For example, in many cases increasing the pressure was found to result in lower minimum heating targets on a per unit $\mathrm{SO}_{2}$ production basis, despite the fact that $\mathrm{SO}_{2}$ conversion was reduced. Consequently, the decision was made to use a statistical method to explore the entire feasible operating envelope and identify the conditions under which the minimum heating target would be at its lowest possible value. This approach was used as described below to quantify the performance potential of the high-temperature bayonet decomposition reactor.

\subsection{Statistical Design of Model Experiments and Analyses.}

The use of statistically-based computer model experiments has evolved over the last few years. Santner et al. identify three types of variables that can affect the output of a computer code depending on the phenomenon being modeled and describe several fundamental goals for computer experiments depending on which types of variables are present. ${ }^{16}$ In keeping with their framework, all of the variables involved in the pinch analysis are of a single type - control variables. Control variables are also called engineering or manufacturing variables. They can be set by the engineer or scientist to "control" the product or process, and they are of interest when the output of a computer experiment is a measure of the performance of a product or process. This is the case for the pinch analysis, where the primary performance measure is $Q_{H, m i n}$, the 
high-temperature heat target, and the experimental goal is to find the settings of the control variables that yield the minimum value for $Q_{H, \min }$.

The first step of this analysis was to select a set of inputs, an experimental design, over which the pinch analysis was to be conducted. Since the functional form of the true relationship between the response and inputs was not known, a design strategy was needed that allowed fitting a variety of models and that would provide information about all portions of the experimental region. In pursuit of that strategy, the initial design would have to consist of experimental points uniformly spread throughout the experimental region. That was the approach taken here. Initially, a space-filling design was developed using the commercially-available statistical software package JMP Version 7.0.2. ${ }^{17}$ A Latin Hypercube Design (LHD) was chosen where each factor had as many levels as there were runs in the design, and the levels were spaced evenly from the lower end to the upper end of possible values of the factor. The design chose points to maximize the minimum distance between design points, but with a constraint. The constraint maintained even spacing of the levels of each factor.

The next step was to pursue the development of a comprehensive model relating the $Q_{H, \text { min }}$ response to the levels of the control variables. This approach, if successful, would provide insight into the appropriate functional form (e.g., interactions among the input variables) to represent the mechanisms underlying the relationship between the inputs and the resulting $Q_{H, \min }$ values as well as providing the framework for minimizing the $Q_{H, \text { min }}$ value over the factor space. Approaches used included regression modeling (with random subsets of the data excluded from the model and used instead for validating), neural network modeling, and heuristic methods (supplementing the LHD with additional runs to identify input values that minimize the $Q_{H, \text { min }}$ ).

\section{Results}


4.1. Operating Variable Domain. Before analysis could begin, the operating limits of the decomposition reactor had to be established. Table 1 lists the intervals of possible values of the control variables that were used.

Table 1. Intervals of Possible Values for the Control Variables

\begin{tabular}{lccccccc}
\hline & $\begin{array}{c}\Delta T_{\text {min,recup }}, \\
{ }^{\circ} \mathrm{C}\end{array}$ & $\begin{array}{c}\Delta T_{\text {eq }}, \\
{ }^{\circ} \mathrm{C}\end{array}$ & $\begin{array}{c}P_{i}, \\
\text { bar }\end{array}$ & $\begin{array}{c}T_{\text {cat }}, \\
{ }^{\circ} \mathrm{C}\end{array}$ & $\begin{array}{c}T_{i}, \\
{ }^{\circ} \mathrm{C}\end{array}$ & $\begin{array}{c}T_{\max }, \\
{ }^{\circ} \mathrm{C}\end{array}$ & $\begin{array}{c}x_{i}, \\
\text { mole fraction } \mathrm{SO}_{3}\end{array}$ \\
\hline minimum & 10 & -25 & 10 & 600 & 48 & 750 & 0.068 \\
maximum & 100 & 0 & 90 & 740 & 150 & 900 & 0.384
\end{tabular}

Pressure is dictated by the pressure of the helium coolant, which may be as high as 90 bar, depending on the specific advanced gas-cooled reactor design used as the heat source. Minimizing pressure differentials between the helium and process sides of the decomposition reactor will make seals easier to maintain and will allow thinner bayonet walls to be used for better heat transfer. However, application of Le Châtelier's principle indicates that the decomposition reaction equilibrium is favored by lower pressure. Consequently, a pressure range of 10 to 90 bar was considered.

Reactor heat source (primary coolant) outlet temperatures as high as $1,000^{\circ} \mathrm{C}$ have been proposed, although $950^{\circ} \mathrm{C}$ is a more likely upper limit. That implies the secondary coolant supply temperature could be as high as 900 to $950^{\circ} \mathrm{C}$, resulting in decomposition reactor peak temperatures as high as $900^{\circ} \mathrm{C}$. Since the catalytic $\mathrm{SO}_{3}$ decomposition reaction is negligible below about 650 to $675^{\circ} \mathrm{C},{ }^{18}$ the catalyst bed outlet temperature should be higher, making $750^{\circ} \mathrm{C}$ a reasonable, practical lower limit. Figure 5 illustrates how high-temperature heat would be transferred from an advanced helium gas-cooled nuclear reactor to the sulfuric acid decomposition reactor, using a secondary coolant loop to isolate the nuclear process from the chemical process. The primary interchanger is assumed to have a $50^{\circ} \mathrm{C}$ temperature drop, while 
the process heat exchanger (which is actually the bayonet reactor) is assumed to have a $25^{\circ} \mathrm{C}$ temperature drop.

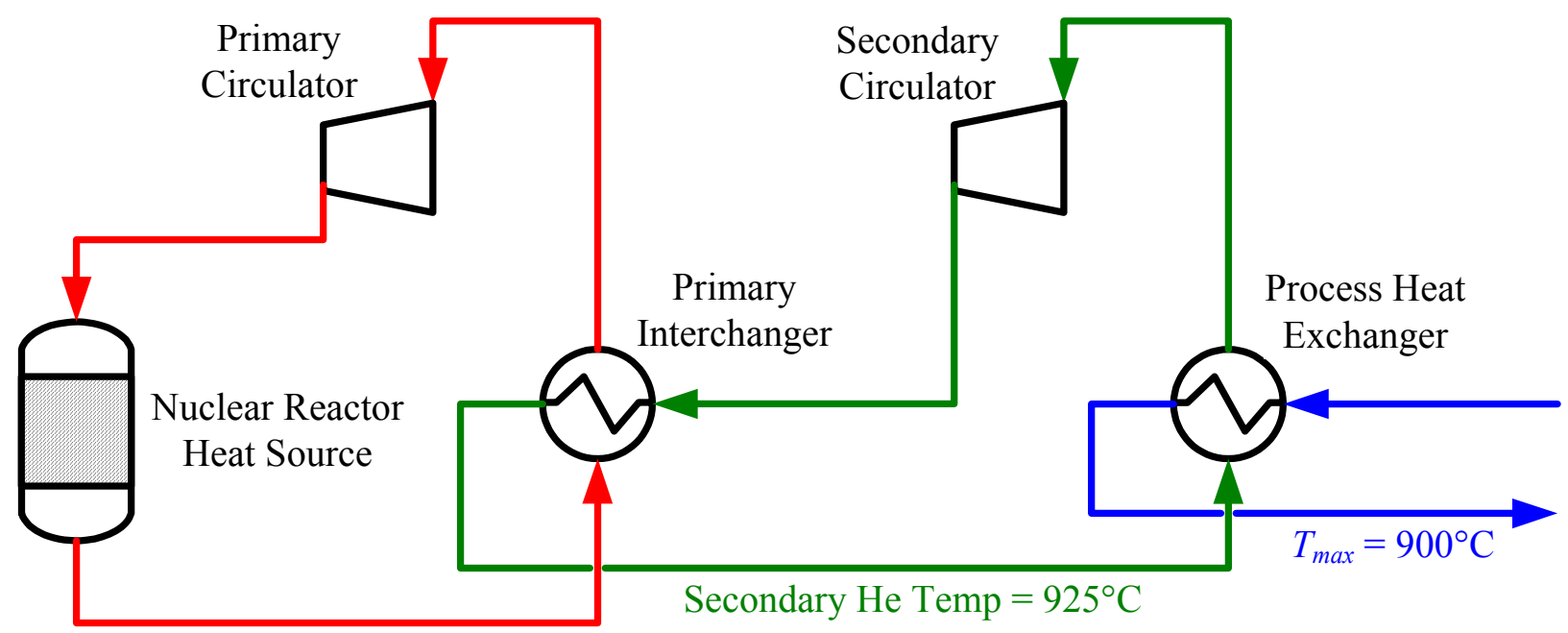

Reactor Outlet Temp $=975^{\circ} \mathrm{C}$

Figure 5. Schematic diagram for an indirectly heated sulfuric acid decomposition process showing the relationship between the primary and secondary helium coolant loops and the process, with a reactor outlet temperature of $975^{\circ} \mathrm{C}$, a $50^{\circ} \mathrm{C}$ temperature difference between the primary and secondary loops, and a minimum temperature difference for helium-to-process fluid heat transfer, $\Delta T_{\min , \mathrm{He}}=25^{\circ} \mathrm{C}$, resulting in a maximum process fluid temperature, $T_{\max }=900^{\circ} \mathrm{C}$.

Flowsheets for the two leading sulfur cycles show sulfuric acid solutions produced in the $50-$ to $60-\mathrm{wt} \%$ range and subsequently concentrated by flash evaporation or distillation. ${ }^{7,9,18}$ Lower acid concentrations would allow more efficient electrolyzer operation in the hybrid sulfur cycle due to lower reversible potential, ${ }^{19}$ so concentrations as low as $30 \mathrm{wt} \%$ (expressed as 0.068 mole fraction $\mathrm{SO}_{3}$, where 1 mole $\mathrm{H}_{2} \mathrm{SO}_{4}$ is equivalent to 1 mole $\mathrm{H}_{2} \mathrm{O}+1$ mole $\mathrm{SO}_{3}$ ) were considered. A value of $90 \mathrm{wt} \%$ (0.384 mole fraction $\left.\mathrm{SO}_{3}\right)$ was used for the upper limit.

As for the temperature of the bayonet reactor feed, values between $48^{\circ} \mathrm{C}$ (conservative lower limit for water-cooled process streams) and $150^{\circ} \mathrm{C}$ (conservative upper limit for polymeric seals) were considered. Limits for the other control variables were assigned based on engineering judgment such that all conceivable situations would be included. 
Table 1 is the factor space for the control variables and corresponds to the values of the inputs for the Aspen Plus/Aspen Energy Analyzer model over which the study of the minimum $Q_{H, \min }$ response was conducted. This is the experimental domain, and a point in this domain corresponds to a specific set of values of the inputs.

4.2. Experimental Design. JMP was used to generate an 80-point LHD. Figure 6 provides a scatter plot matrix of the resulting experimental design. As indicated in this plot, the design yields good coverage of the factor space at least to the extent that these two-dimensional plots provide. These 80 points define the initial set of inputs used to explore the responses of the pinch analysis over the factor space defined by Table 1 . 


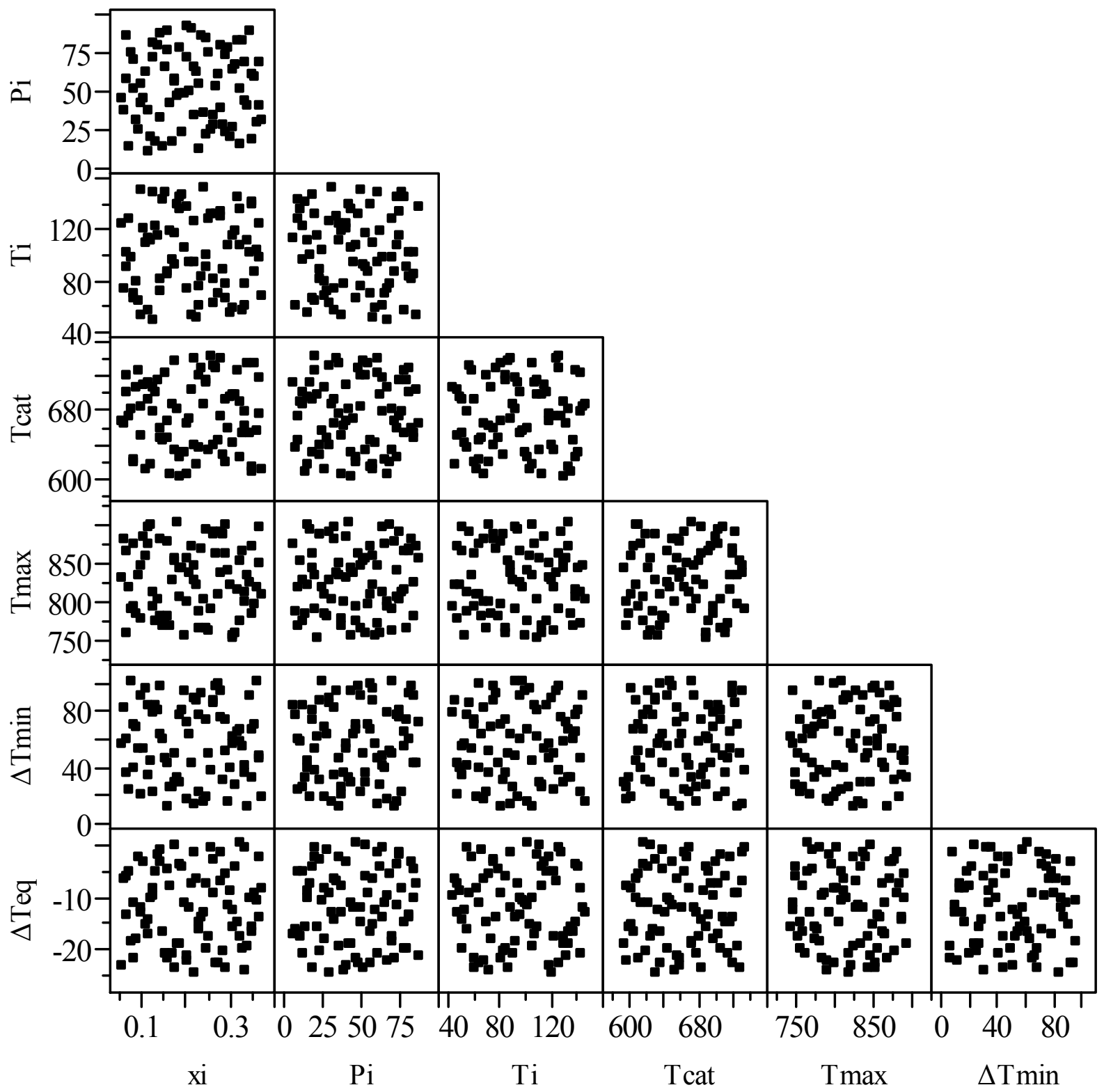

Figure 6. Scatter plot matrix of 80-point LHD generated by JMP showing the coverage of the factor space provided by this space-filling design.

\subsection{Statistical Analysis. The initial goal of the statistical analysis of the data generated}

by simulating the experimental points of the LHD was to develop a comprehensive model

relating the $Q_{H, \min }$ response to the levels of the control variables. While the modeling effort was not deemed successful, the experimental design did provide insight. Figure 7 shows the most 
interesting plot of the primary response of interest, $Q_{H, \min }$, versus the inputs. It is a plot of the $Q_{H, \text { min }}$ values versus the $x_{i}$ values, the $\mathrm{SO}_{3}$ feed mole fractions of the experimental runs. The plot indicates a curvilinear effect on the value of $Q_{H, \min }$ as $x_{i}$ increases over the interval from 0.068 to 0.384

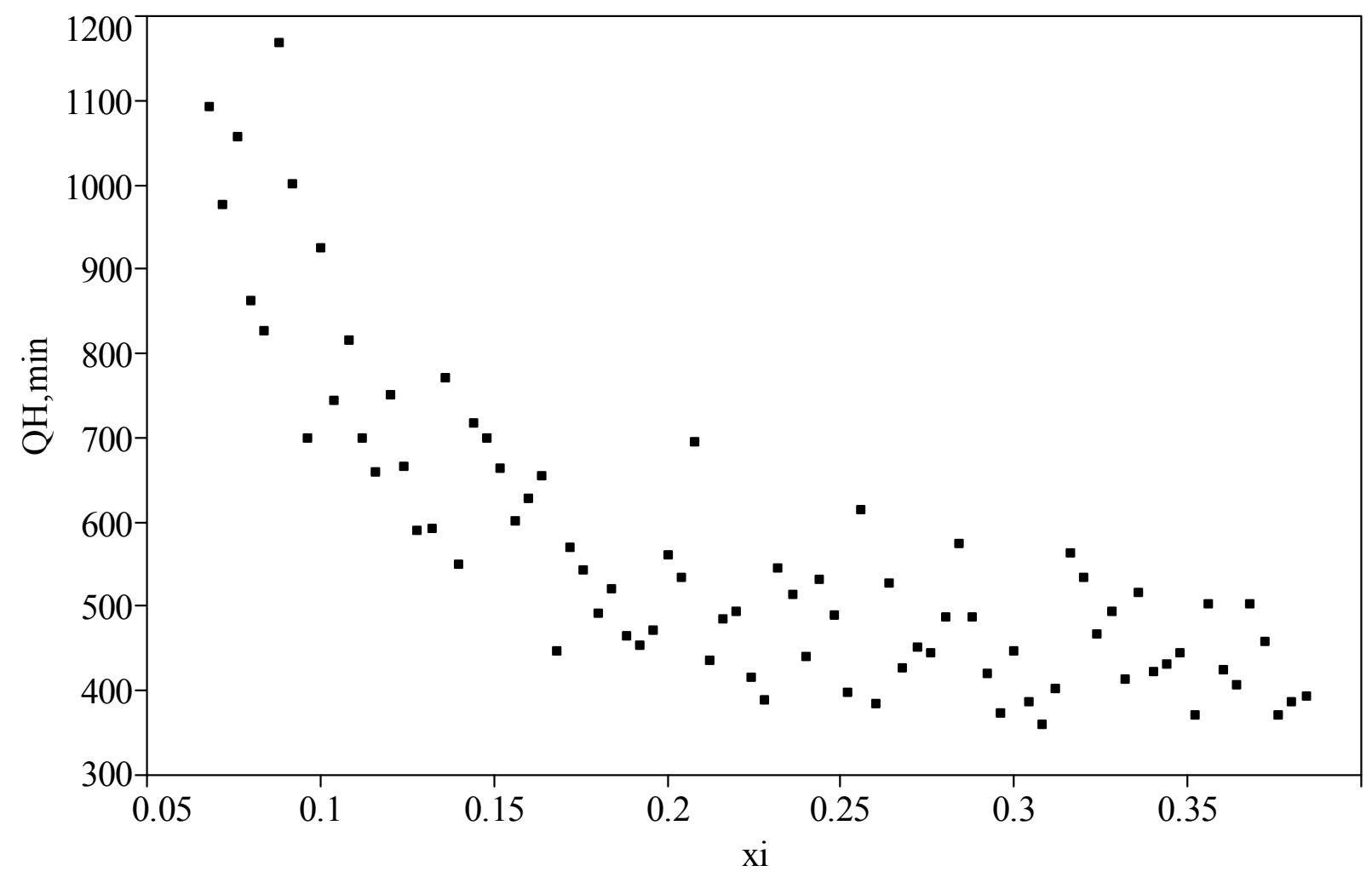

Figure 7. Plot of the $Q_{H, \min }$ value versus $x_{i}$ calculated from Aspen Plus/Aspen Energy Analyzer for the 80-point LHD generated by JMP.

Looking at Figure 7, the lowest feed concentration that satisfies the feasibility criterion $Q_{H, \text { min }}<450 \mathrm{~kJ} / \mathrm{mol} \mathrm{SO}_{2}$ is $x_{i}=0.168$, which corresponds to an $\mathrm{H}_{2} \mathrm{SO}_{4}$ content of $57.9 \mathrm{wt} \%$. The lowest value of $x_{i}$ for which $Q_{H, \min }<400 \mathrm{~kJ} / \mathrm{mol} \mathrm{SO}_{2}$ is 0.228 , about $69.5 \mathrm{wt} \% \mathrm{H}_{2} \mathrm{SO}_{4}$. Finally, the lowest value of $Q_{H, \min }$ obtained in this 80 -point LHD, $357.6 \mathrm{~kJ} / \mathrm{mol} \mathrm{SO}_{2}$, was observed at a feed concentration of 0.308 , equivalent to an $\mathrm{H}_{2} \mathrm{SO}_{4}$ content of $81.4 \mathrm{wt} \%$. Given the fact that the sulfuric acid product of the Bunsen reaction in the SI cycle is roughly $57 \mathrm{wt} \% \mathrm{H}_{2} \mathrm{SO}_{4},{ }^{3}$ and the 
electrolyzer acid product in the HyS cycle may be $\leq 50 \mathrm{wt} \% \mathrm{H}_{2} \mathrm{SO}_{4},{ }^{7}$ this suggests that an acid concentration step will be needed in order to integrate the bayonet decomposition reactor into a practical sulfur cycle process.

4.4. Minimum Heating Target. Since there was no success in developing a comprehensive model which could be used to direct the search for levels of the input variables that lead to a minimum value for $Q_{H, \min }$, a more heuristic approach was taken. That is, the LHD results were supplemented with additional runs which provided additional guidance for the conditions leading to a minimum of $Q_{H, \min }$. Specifically, larger values for $P_{i}$ and $T_{\max }$ and smaller values of $\Delta T_{\text {min,recup }}$ and $-\Delta T_{e q}$ led to smaller $Q_{H, \text { min }}$ values. In addition, the $Q_{H, \text { min }}$ values appeared to be insensitive to the values for the feed temperature, $T_{i}$, and the catalyst bed inlet temperature, $T_{\text {cat }}$. (A value of $T_{c a t}=675^{\circ} \mathrm{C}$ was used for all of the supplementary simulations, giving the misleading impression that this represents an optimal value.) Thus, the smallest values of $Q_{H, \min }$ are associated with $P_{i}=90 \mathrm{bar}, T_{\max }=900^{\circ} \mathrm{C}, \Delta T_{\text {min, recup }}=10^{\circ} \mathrm{C}$, and $-\Delta T_{e q}=0^{\circ} \mathrm{C}$.

These results make physical sense. Increasing $T_{\max }$ favors the decomposition equilibrium conversion, so less sulfuric acid needs to be boiled per mole of $\mathrm{SO}_{2}$ produced. (The effect of $T_{\max }$ on $Q_{H, m i n}$ is illustrated in Figure 8, with the lower bound extended beyond $750^{\circ} \mathrm{C}$ to $700^{\circ} \mathrm{C}$.) Since $-\Delta T_{e q}$ represents a departure from the decomposition equilibrium, setting it equal to zero also adds to $\mathrm{SO}_{2}$ production. Minimizing $\Delta T_{\text {min,recup }}$ maximizes the amount of heat that can be recovered by interchange from the cold feed to the hot product. All three of these act to make $Q_{H, \min }$ as small as possible. 


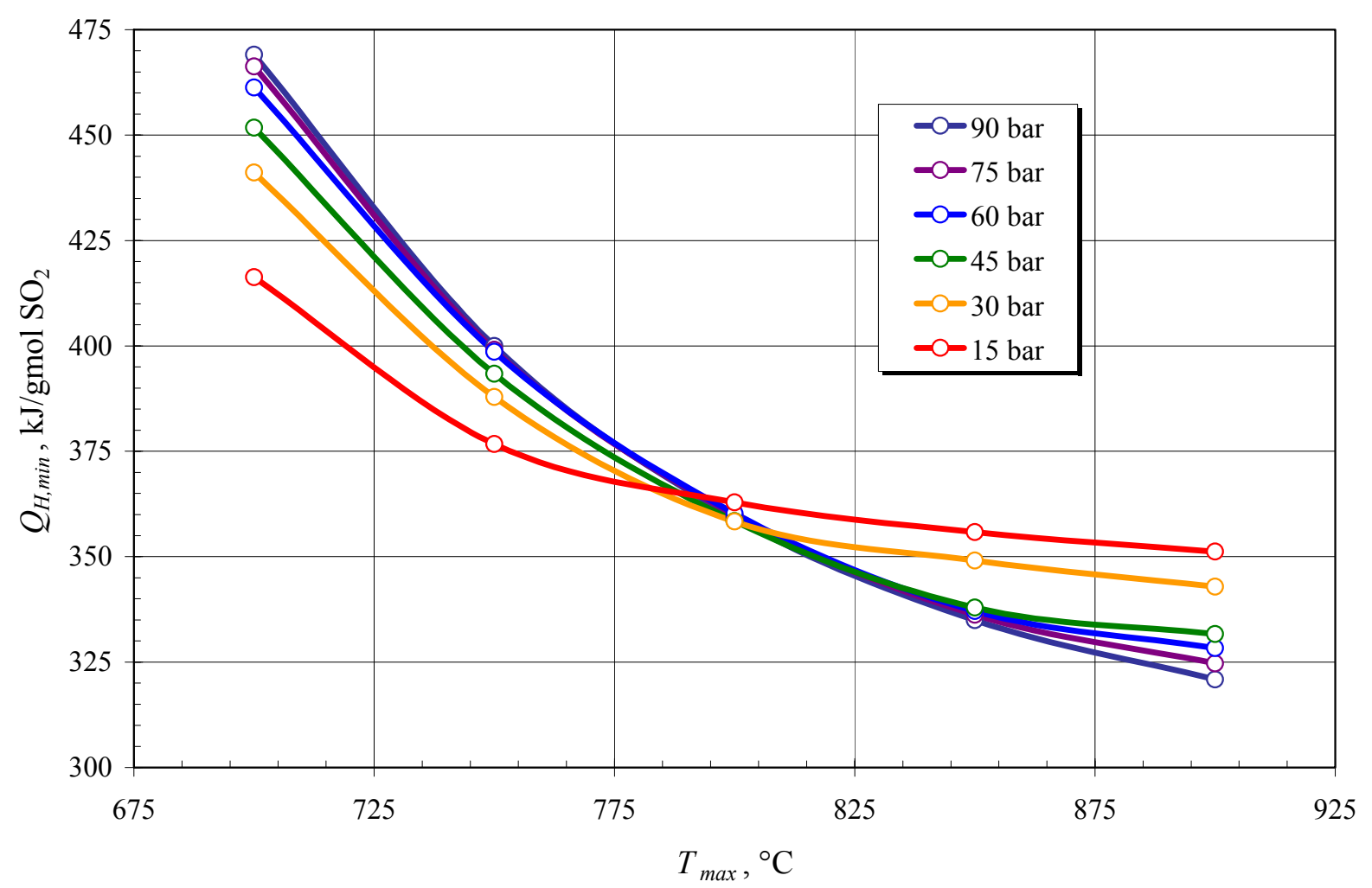

Figure 8. Effect of $T_{\max }$ on $Q_{H, \min }$ at various $P_{i}\left(x_{i}=0.298, T_{i}=25^{\circ} \mathrm{C}, T_{c a t}=675^{\circ} \mathrm{C},-\Delta T_{e q}=0\right.$, and $\Delta T_{\text {min, recup }}=10^{\circ} \mathrm{C}$ )

The pressure effect is less obvious. As noted earlier, Le Châtelier's principle indicates that lower pressure favors the decomposition equilibrium conversion. Therefore, the opportunity for recuperation must decrease to a greater extent, such that it overrides the beneficial effect of increased conversion. This can be seen in Table 2, which compares the effect of pressure on $Q_{H, \min }, Q_{R, \max }$, and $X$ at several different temperatures. 
Table 2. Effect of $P_{i}$ on $Q_{H, \min }, X$, and $Q_{R, \max }$ at Various $T_{\max }\left(x_{i}=0.298, T_{i}=25^{\circ} \mathrm{C}, T_{c a t}=\right.$ $675^{\circ} \mathrm{C},-\Delta T_{e q}=0$, and $\Delta T_{m i n, \text { recup }}=10^{\circ} \mathrm{C}$ ); Normalized (with Respect to 90-bar Operation) Values Included in Last 3 Columns

\begin{tabular}{|c|c|c|c|c|c|c|c|}
\hline$P_{i}$, bar & $T_{\max },{ }^{\circ} \mathrm{C}$ & $\underset{\mathrm{kJ} / \mathrm{mol} \mathrm{SO}_{2}}{Q_{H, \min }}$ & $X$ & $\underset{\mathrm{kJ} / \mathrm{mol} \mathrm{SO}_{2}}{Q_{R, \max }}$ & $q_{H, 90}$ & $\chi_{90}$ & $q_{R, 90}$ \\
\hline 90 & 900 & 320.9 & 0.5181 & 561.1 & 1.000 & 1.000 & 1.000 \\
\hline 75 & 900 & 324.7 & 0.5400 & 526.8 & 1.012 & 1.042 & 0.939 \\
\hline 60 & 900 & 328.3 & 0.5660 & 489.6 & 1.023 & 1.093 & 0.873 \\
\hline 45 & 900 & 331.6 & 0.5985 & 448.2 & 1.033 & 1.155 & 0.799 \\
\hline 30 & 900 & 342.9 & 0.6422 & 391.3 & 1.069 & 1.240 & 0.697 \\
\hline 15 & 900 & 351.2 & 0.7110 & 321.9 & 1.094 & 1.372 & 0.574 \\
\hline 90 & 850 & 334.9 & 0.4279 & 688.1 & 1.000 & 1.000 & 1.000 \\
\hline 75 & 850 & 336.2 & 0.4497 & 644.2 & 1.004 & 1.051 & 0.936 \\
\hline 60 & 850 & 337.1 & 0.4760 & 596.7 & 1.006 & 1.112 & 0.867 \\
\hline 45 & 850 & 337.9 & 0.5091 & 543.3 & 1.009 & 1.190 & 0.790 \\
\hline 30 & 850 & 349.1 & 0.5546 & 469.3 & 1.042 & 1.296 & 0.682 \\
\hline 15 & 850 & 355.8 & 0.6289 & 378.4 & 1.062 & 1.470 & 0.550 \\
\hline 90 & 800 & 359.3 & 0.3346 & 886.9 & 1.000 & 1.000 & 1.000 \\
\hline 75 & 800 & 359.9 & 0.3553 & 823.9 & 1.002 & 1.062 & 0.929 \\
\hline 60 & 800 & 360.3 & 0.3803 & 756.0 & 1.003 & 1.137 & 0.852 \\
\hline 45 & 800 & 358.5 & 0.4123 & 682.4 & 0.998 & 1.232 & 0.769 \\
\hline 30 & 800 & 358.3 & 0.4570 & 593.3 & 0.997 & 1.366 & 0.669 \\
\hline 15 & 800 & 362.9 & 0.5324 & 470.0 & 1.010 & 1.591 & 0.530 \\
\hline 90 & 750 & 400.0 & 0.2438 & 1216.4 & 1.000 & 1.000 & 1.000 \\
\hline 75 & 750 & 399.1 & 0.2624 & 1119.3 & 0.998 & 1.076 & 0.920 \\
\hline 60 & 750 & 398.6 & 0.2850 & 1015.7 & 0.997 & 1.169 & 0.835 \\
\hline 45 & 750 & 393.4 & 0.3141 & 906.6 & 0.983 & 1.289 & 0.745 \\
\hline 30 & 750 & 387.9 & 0.3553 & 779.4 & 0.970 & 1.457 & 0.641 \\
\hline 15 & 750 & 376.7 & 0.4267 & 616.6 & 0.942 & 1.750 & 0.507 \\
\hline 90 & 700 & 469.1 & 0.1616 & 1808.6 & 1.000 & 1.000 & 1.000 \\
\hline 75 & 700 & 466.3 & 0.1774 & 1640.2 & 0.994 & 1.097 & 0.907 \\
\hline 60 & 700 & 461.3 & 0.1966 & 1468.6 & 0.983 & 1.216 & 0.812 \\
\hline 45 & 700 & 451.8 & 0.2215 & 1290.1 & 0.963 & 1.371 & 0.713 \\
\hline 30 & 700 & 441.1 & 0.2571 & 1089.0 & 0.940 & 1.590 & 0.602 \\
\hline 15 & 700 & 416.3 & 0.3197 & 845.1 & 0.888 & 1.978 & 0.467 \\
\hline
\end{tabular}


At a peak process fluid temperature of $900^{\circ} \mathrm{C}$ (all other control variables set as indicated in Table 2), decreasing the pressure from 90 to 15 bar causes a $9.4 \%$ increase in the heating target. The last two columns in Table 2 suggest that this results from the interaction of a $+37.2 \%$ change in fractional conversion with a $-42.6 \%$ change in recuperation. As the peak process temperature is lowered in $50^{\circ} \mathrm{C}$ decrements, however, decreasing the pressure from 90 to 15 bar has an increasingly bigger effect on fractional conversion than it does on recuperation. At $T_{\max }=$ $800^{\circ} \mathrm{C}$, the $Q_{H, \min }$ response is fairly flat, while at $700^{\circ} \mathrm{C}$, the pressure effect is reversed. That is because the change in fractional conversion has almost tripled between $900^{\circ} \mathrm{C}$ and $700^{\circ} \mathrm{C}$, while the magnitude of the change in recuperation has only grown by a quarter. (The reversal of the pressure effect as $T_{\max }$ passes through $800^{\circ} \mathrm{C}$ is illustrated in Figure 9.)

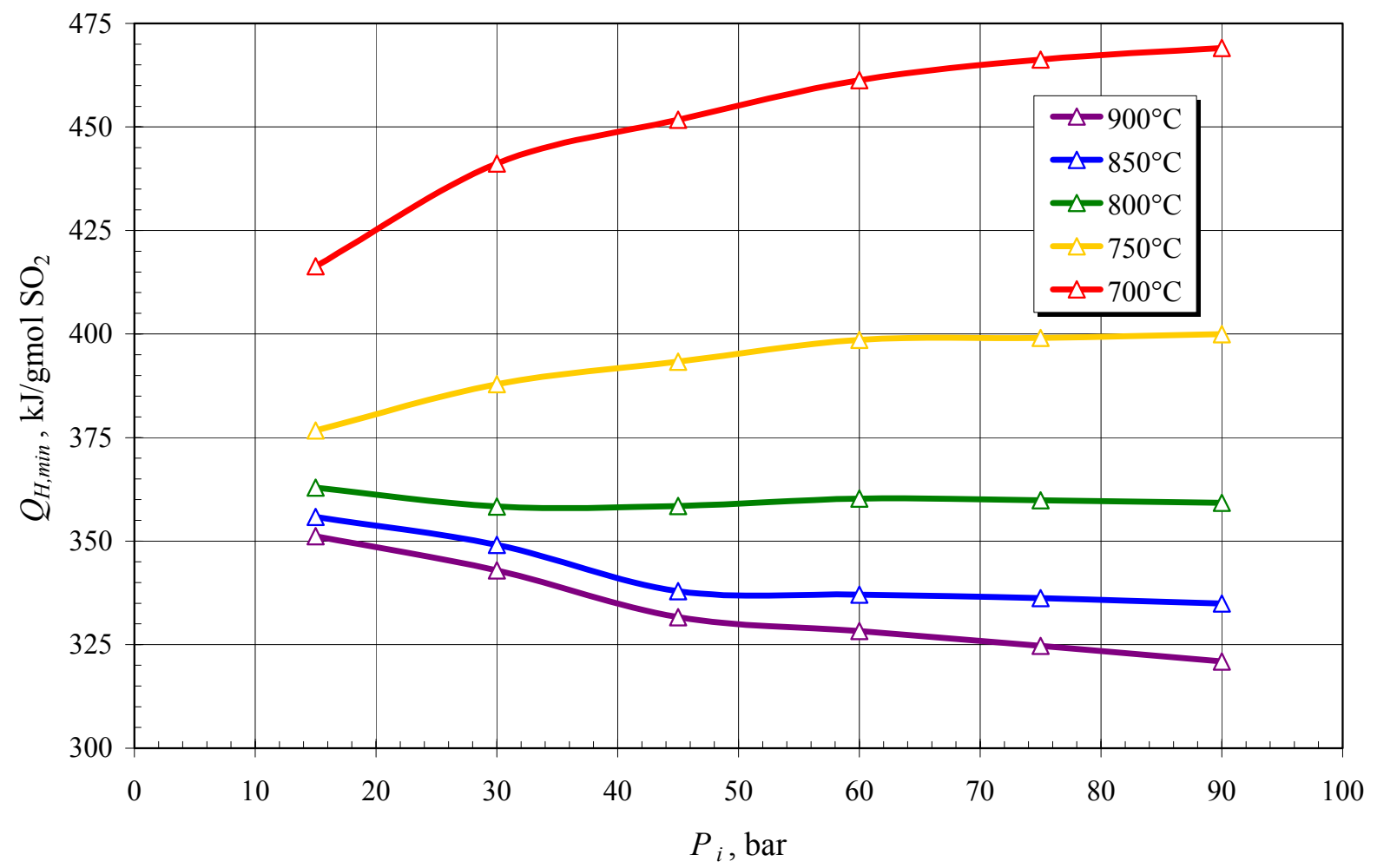

Figure 9. Effect of $P_{i}$ on $Q_{H, \min }$ at various $T_{\max }\left(x_{i}=0.298, T_{i}=25^{\circ} \mathrm{C}, T_{c a t}=675^{\circ} \mathrm{C},-\Delta T_{e q}=0\right.$, and $\Delta T_{\text {min, recup }}=10^{\circ} \mathrm{C}$ ) 
The fact that $T_{i}$ and $T_{c a t}$ have no effect on $Q_{H, \min }$ also makes physical sense. The inlet temperature, $T_{i}$, should not affect the heating target since it has no impact on the heating curve above the pinch temperature. As for the catalyst bed inlet temperature, $T_{\text {cat }}$, given the assumed operating variable domain in Table 1, its range is sufficiently high enough that it does not influence the pinch temperature. Since the product composition is determined by the catalyst bed outlet temperature, $T_{\max }$, rather than $T_{c a t}$, it has no impact on the product enthalpy either, which renders it incapable of affecting $Q_{H, m i n}$.

A plot of the complete set of $Q_{H, \min }$ versus $x_{i}$ values generated as part of this study is provided in Figure 10. Here the values for $Q_{H, \min }$ that are shaded in red fall in the critical interval of $x_{i}$ values over which $Q_{H \text {,min }}$ is minimized. For the red-shaded values, the other factors are at one of their extremes (except for $T_{c a t}=675^{\circ} \mathrm{C}$ and $T_{i}$, which has no influence on $Q_{H, m i n}$ ): $P_{i}$ and $T_{\max }$ at their maxima, $-\Delta T_{e q}$ and $\Delta T_{\text {min,recup }}$ at their minima. The results also indicate that the minimum $Q_{H, \text { min }}$ value for the operating variable domain in Table 1 is $320.9 \mathrm{~kJ} / \mathrm{mol} \mathrm{SO}_{2}$, and that it occurs at a value of $x_{i}=0.298$ (first entry in Table 2). 


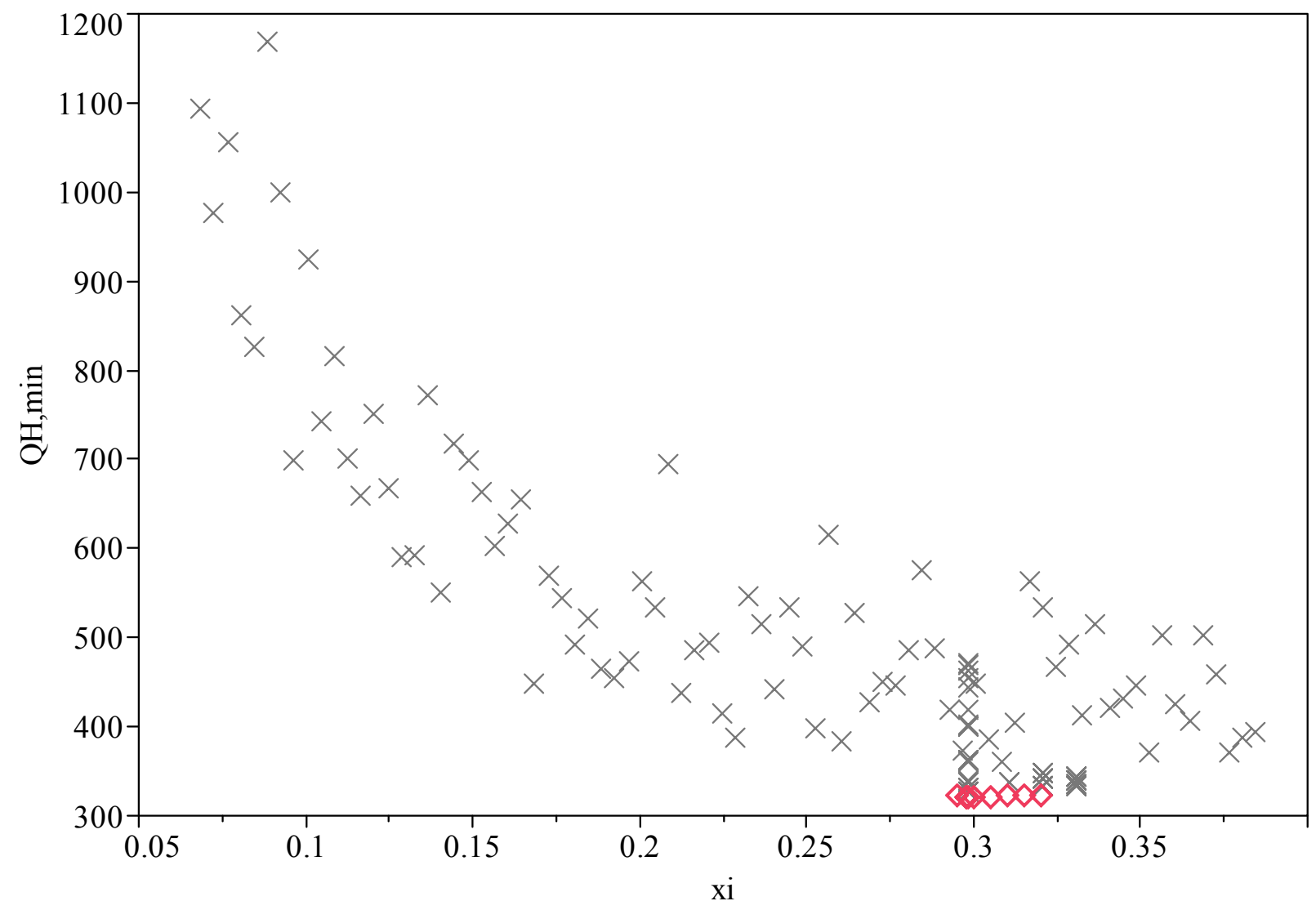

Figure 10. A plot of the $Q_{H, \min }$ values versus $x_{i}$ values, with the points highlighted in red corresponding to the other factor levels fixed at their maxima except for $T_{\text {cat }}$ and the temperature of the feed, $T_{i}$.

A closer look at the $Q_{H, \min }$ minimum is provided in Figure 11 . The lower curve shows the effect of feed composition on the minimum heat requirement with all other control variables at their optimum levels ( $T_{\max }$ and $P_{i}$ at their maxima, $-\Delta T_{e q}$ and $\Delta T_{\text {min, recup }}$ at their minima). While the optimum $\mathrm{SO}_{3}$ feed mole fraction is 0.298 , any mole fraction value between 0.28 and 0.34 will allow $Q_{H, \min }$ to come well within $2 \%$ of the optimal $320.9 \mathrm{~kJ} / \mathrm{mol} \mathrm{SO}_{2}$ target. 


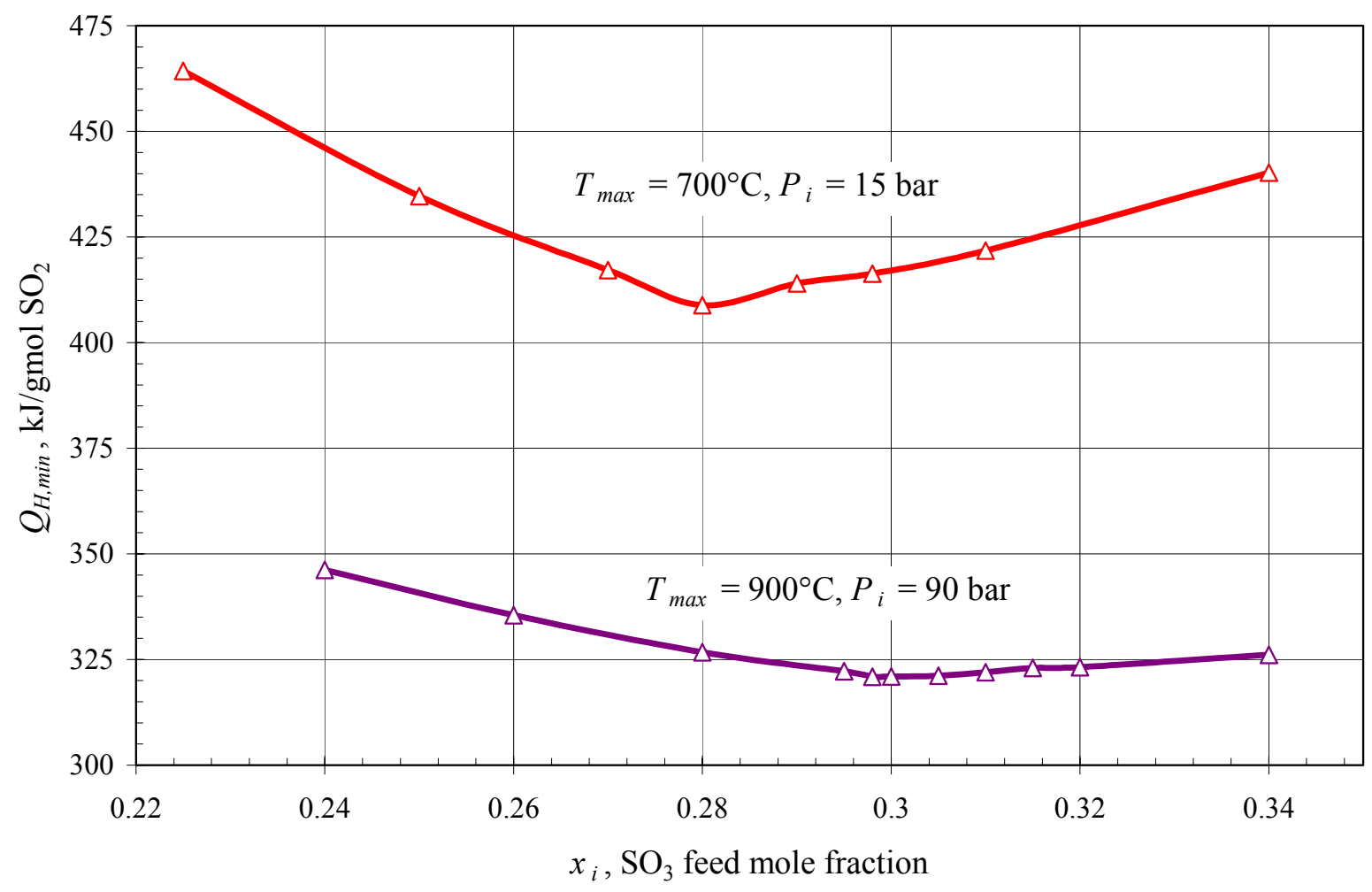

Figure 11. A plot of the $Q_{H, \min }$ values versus $x_{i}$ values, at the stated $T_{\max }$ and $P_{i}$ combinations $\left(T_{i}\right.$ $=25^{\circ} \mathrm{C}, T_{\text {cat }}=675^{\circ} \mathrm{C},-\Delta T_{e q}=0$, and $\Delta T_{\text {min, } \text {,ecup }}=10^{\circ} \mathrm{C}$ )

The upper curve considers the case where the maximum process fluid temperature is limited to $700^{\circ} \mathrm{C}$, which falls outside the original domain of this study. This is an important consideration because the higher the operating temperature of the nuclear heat source, the greater the material challenges, development risks, and capital costs. Gas-cooled reactor designs with helium outlet temperatures as high as $1,000^{\circ} \mathrm{C}$ have been proposed, but there has been considerable interest in the potential for lower reactor temperatures. A maximum process fluid temperature of $700^{\circ} \mathrm{C}$ would imply a reactor helium coolant outlet temperature of approximately $775^{\circ} \mathrm{C}$. This curve shows that the lowest possible heating target for a bayonet decomposition reactor under these conditions is about $409 \mathrm{~kJ} / \mathrm{mol} \mathrm{SO}_{2}$, assuming a bayonet feed pressure of 15 
bar. If substantially higher feed pressures are required (as is likely, to minimize bayonet material thickness and differential pressure across seals), the heating target could increase to $450 \mathrm{~kJ} / \mathrm{mol}$ $\mathrm{SO}_{2}$ or more, based on the pressure effect seen in Figure 9. Given the need for pre-concentration of the feed, which will require additional heat input, it is clear that concentration and decomposition of sulfuric acid will then consume more than $450 \mathrm{~kJ} / \mathrm{mol} \mathrm{SO}_{2}$, making sulfur cycles unable to meet the desired process efficiency goals.

This indicates that the bayonet decomposition reactor will require a high-temperature heat source in excess of $825^{\circ} \mathrm{C}$ to achieve an efficiency advantage over conventional electrolysis.

4.5. Helium Heat Source Pinch Temperature. Having explored the dependence of the minimum heating target on seven control variables, the next topic of interest is the temperature range over which the high-temperature heat source could be applied to the bayonet. If the nuclear reactor coolant inlet and outlet temperatures span a wide enough range, it is conceivable that not all of the heat could be utilized efficiently for sulfuric acid decomposition. In that case, some of the heat would need to be used for alternative purposes, e.g. steam or power generation.

The lower curve in Figure 12 shows the effect of feed composition on the helium heat source pinch temperature with all other control variables at their optimum levels ( $T_{\max }$ and $P_{i}$ at their maxima, $-\Delta T_{e q}$ and $\Delta T_{m i n, r e c u p}$ at their minima), and with $\Delta T_{m i n, H e}$, the minimum temperature difference for helium-to-process fluid heat transfer, equal to $25^{\circ} \mathrm{C}$. 


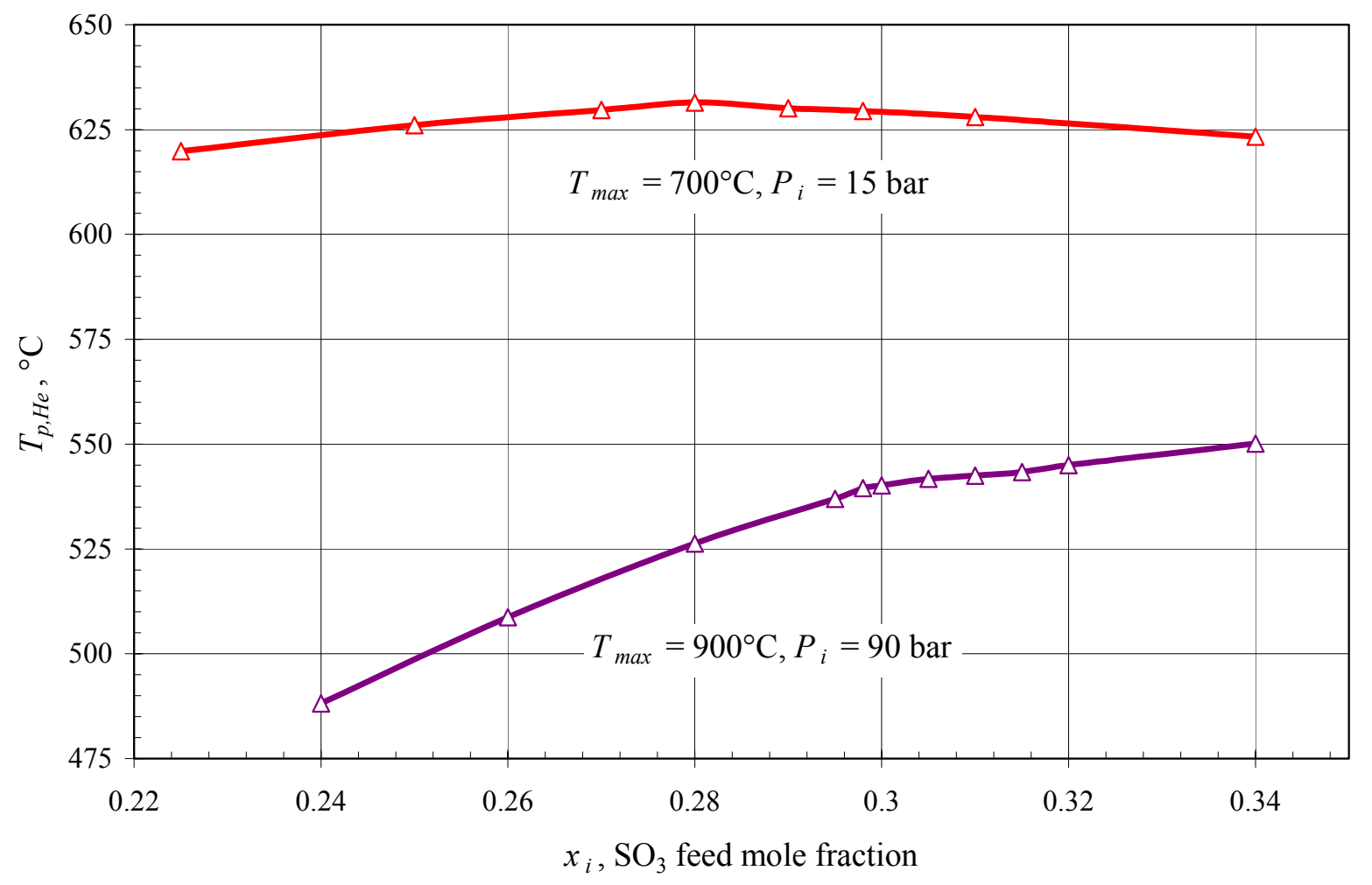

Figure 12. A plot of the $T_{p, H e}$ values versus $x_{\boldsymbol{i}}$ values, at the stated $T_{\max }$ and $P_{i}$ combinations $\left(T_{\boldsymbol{i}}\right.$ $=25^{\circ} \mathrm{C}, T_{\text {cat }}=675^{\circ} \mathrm{C},-\Delta T_{e q}=0, \Delta T_{\text {min,recup }}=10^{\circ} \mathrm{C}$, and $\Delta T_{\min , H e}=25^{\circ} \mathrm{C}$ )

With $T_{\max }=900^{\circ} \mathrm{C}$ and $\Delta T_{\min , H e}=25^{\circ} \mathrm{C}$, the secondary coolant supply temperature will be $925^{\circ} \mathrm{C}$. If the primary interchanger has a $50^{\circ} \mathrm{C}$ temperature difference, this implies a reactor outlet temperature of $975^{\circ} \mathrm{C}$. Recalling that the minimum value of the heating target occurs at a $\mathrm{SO}_{3}$ feed mole fraction of 0.298 , the helium pinch temperature at that point is $539.5^{\circ} \mathrm{C}$. This results in a usable secondary helium temperature range of nearly $400^{\circ} \mathrm{C}$ - from a $925^{\circ} \mathrm{C}$ supply temperature to a $539.5^{\circ} \mathrm{C}$ return temperature. Since the primary and secondary coolant flows should be closely matched, the primary coolant temperature range will also be nearly $400^{\circ} \mathrm{C}$. Thus, if the reactor inlet temperature is greater than or equal to $590^{\circ} \mathrm{C}$ (assuming a $975^{\circ} \mathrm{C}$ outlet temperature), all of its heat output could be used for sulfuric acid decomposition. 
Now consider the case where $T_{\max }=700^{\circ} \mathrm{C}$ and $\Delta T_{\min , \mathrm{He}}=25^{\circ} \mathrm{C}$, implying that the secondary coolant supply temperature is $725^{\circ} \mathrm{C}$. This situation, with $P_{i}=15$ bar to minimize $Q_{H, m i n}$, is represented by the upper curve in Figure 12. The minimum target occurs at $x_{i}=0.28$ (Figure 11), for which the helium pinch temperature is $631.4^{\circ} \mathrm{C}$. That means the usable helium temperature range is less than $100^{\circ} \mathrm{C}-$ from a $725^{\circ} \mathrm{C}$ supply temperature to a $631.4^{\circ} \mathrm{C}$ return temperature. The reason for this is that the temperature range over which the catalytic decomposition reaction can take place is compressed.

It was earlier noted that the catalytic $\mathrm{SO}_{3}$ decomposition reaction is negligible below about 650 to $675^{\circ} \mathrm{C},{ }^{18}$ resulting in the somewhat arbitrary choice of the catalyst bed inlet temperature, $T_{\text {cat }}$, being set equal to $675^{\circ} \mathrm{C}$. While the endothermic decomposition can then occur over a $225^{\circ} \mathrm{C}$ range when the peak process fluid temperature is $900^{\circ} \mathrm{C}$, it is limited to a $25^{\circ} \mathrm{C}$ range if the peak temperature is only $700^{\circ} \mathrm{C}$. Thus, at lower peak operating temperatures, the helium pinch temperature becomes determined by the catalyst bed inlet temperature rather than the pinch point. This can be visualized by comparing Figure 13, which illustrates the utility pinch analysis for the $700^{\circ} \mathrm{C}$ case, with Figure 4 . The lower temperature tangent point in Figure 13 is at the catalyst bed inlet, while in Figure 4 it is near the pinch point (where the GCC touches the ordinate). Lowering $T_{\text {cat }}$ would provide some relief, but it is unlikely that the decomposition reaction will take place to any significant extent at the much lower temperatures needed to shift the low-temperature tangent from the catalyst bed inlet to the pinch point. Therefore, operating the bayonet at lower temperatures not only increases the minimum heating target, it also increases the helium pinch temperature, reducing the temperature range over which the helium heat source can be efficiently utilized. 


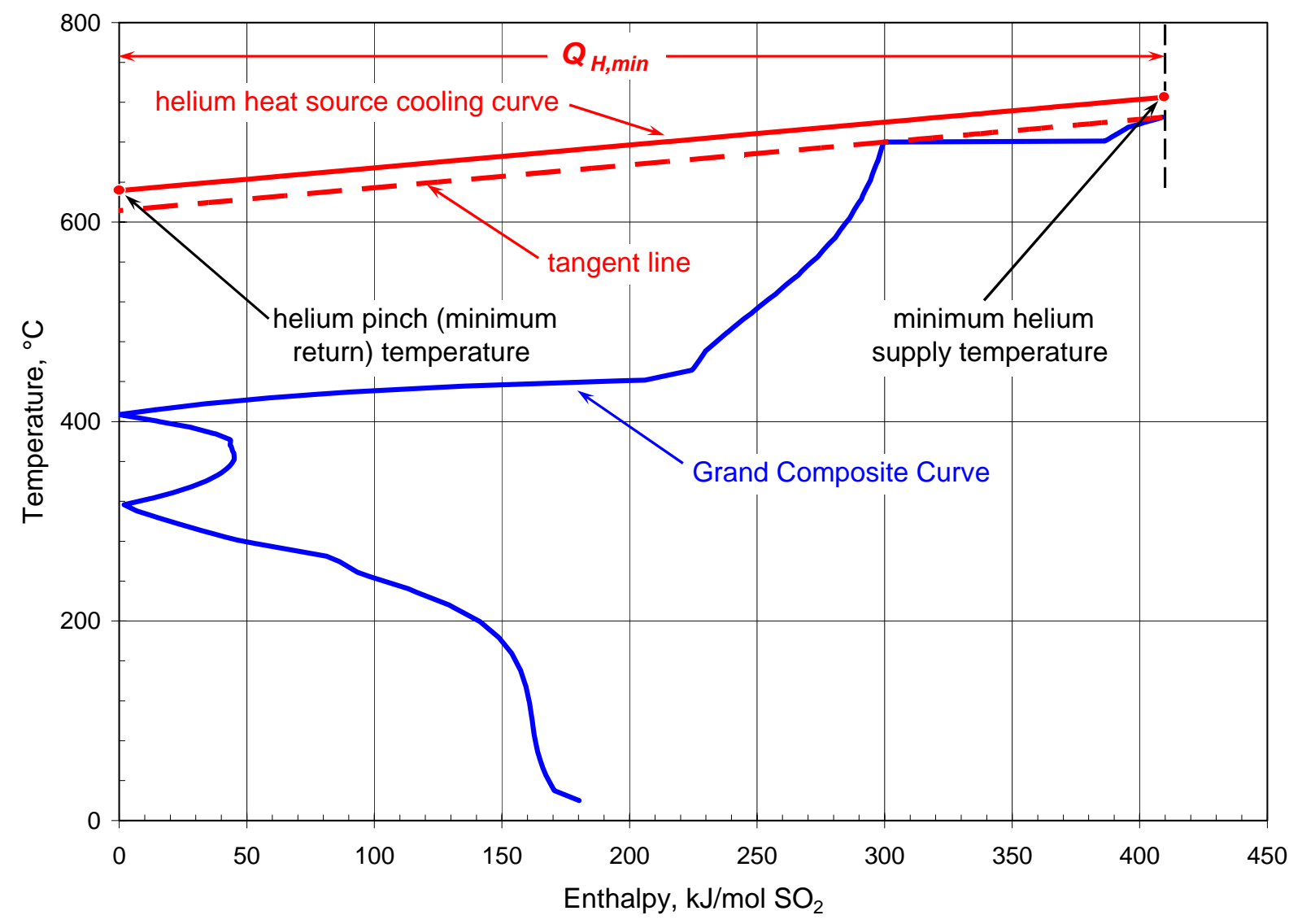

Figure 13. Utility pinch analysis for bayonet decompositon reactor: $28.0 \mathrm{~mol} \% \mathrm{SO}_{3}$ feed at $25^{\circ} \mathrm{C}$ and 15 bar; $675^{\circ} \mathrm{C}$ and $700^{\circ} \mathrm{C}$ catalyst bed inlet and outlet temperatures, respectively; $0^{\circ} \mathrm{C}$ temperature approach to decomposition equilibrium; $10^{\circ} \mathrm{C}$ internal (recuperative), $25^{\circ} \mathrm{C}$ external (helium-to-process fluid) minimum temperature difference.

4.5. Pressure Drop Effects. As noted earlier, the ability to specify pressure drop was included in the model, but was found not to have a material effect on the outcome. This was demonstrated by simulating identical cases with and without pressure drop and comparing the results.

Pressure drop values (in bar units) can be specified for five distinct zones: 1. $\Delta P_{p h b x}$, liquid preheating and boiling; $2 . \Delta P_{\text {spht }}$, vapor superheating; $3 . \Delta P_{c a t}$, catalyst bed; $4 . \Delta P_{c o o l}$, vapor cooling; and 5. $\Delta P_{c n d x}$, partial condensing. The following values were used in simulations that 
duplicated those shown in Figure 11 and Figure 12: $\Delta P_{p h b x}=0.5$ bar, $\Delta P_{\text {spht }}=0.1$ bar, $\Delta P_{\text {cat }}=1.0$ bar, $\Delta P_{\text {cool }}=0.1 \mathrm{bar}$, and $\Delta P_{c n d x}=0.3 \mathrm{bar}$, for a total pressure drop across the bayonet of $\Delta P=2.0$ bar. Results are shown in Figure 14 and Figure 15.

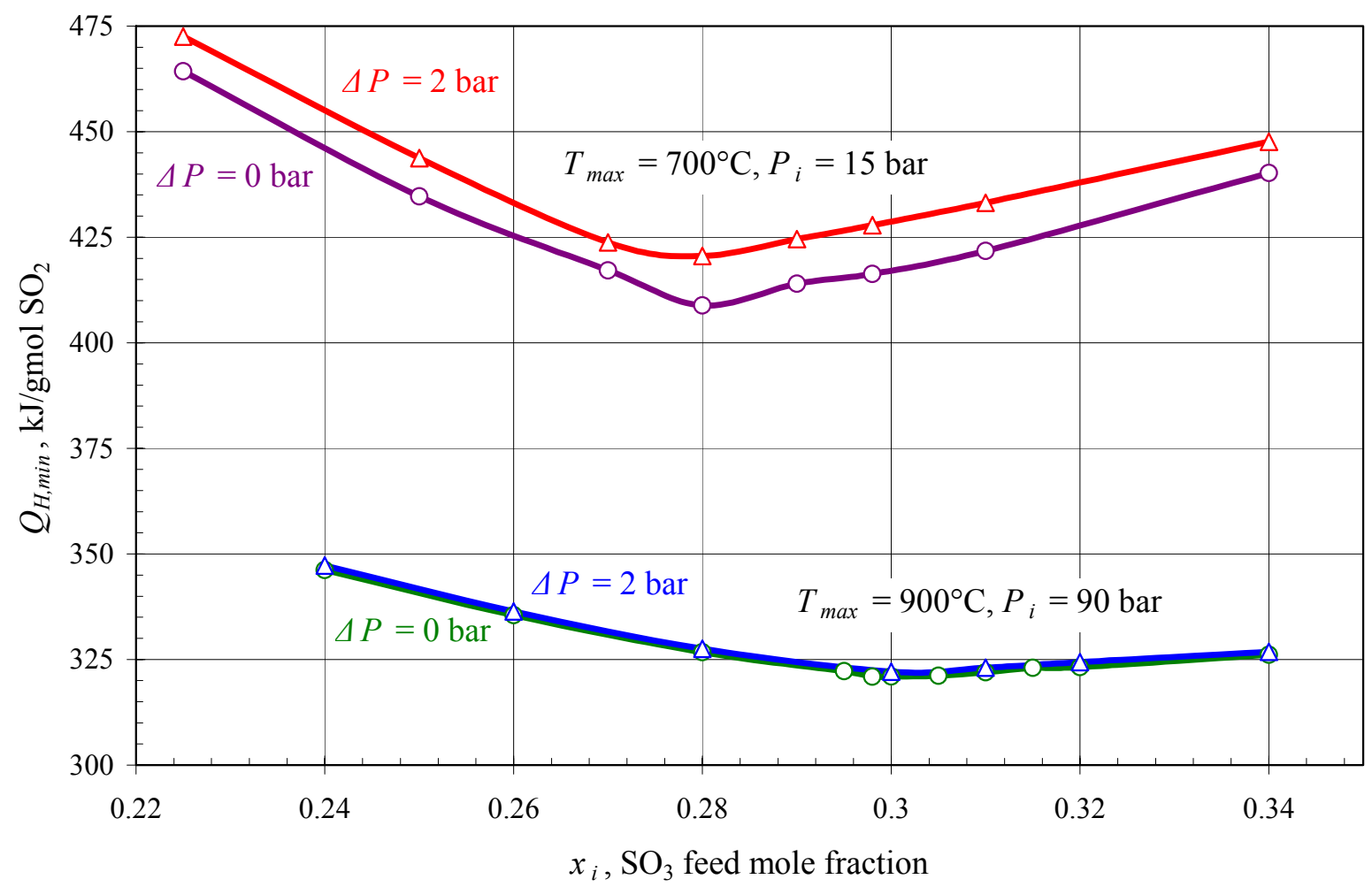

Figure 14. A plot of the $Q_{H, \min }$ values versus $x_{\boldsymbol{i}}$ values, at the stated $T_{\max }$ and $P_{i}$ combinations, with $\Delta P=0$ or $2 \operatorname{bar}\left(T_{i}=25^{\circ} \mathrm{C}, T_{\text {cat }}=675^{\circ} \mathrm{C},-\Delta T_{e q}=0\right.$, and $\left.\Delta T_{\text {min, recup }}=10^{\circ} \mathrm{C}\right)$; if $\Delta P=2$ bar, then $\Delta P_{p h b x}=0.5, \Delta P_{\text {spht }}=0.1, \Delta P_{c a t}=1.0, \Delta P_{\text {cool }}=0.1$, and $\Delta P_{c n d x}=0.3$ bar, else all $\Delta P \mathrm{~s}=0$.

With regard to the minimum heating target (Figure 14), adding pressure drop while holding all else constant increases the value of $Q_{H, \min }$. The effect is essentially negligible at high pressure, as shown by the lower pair of curves ( 0.2 to $0.4 \%$ higher at 90 bar). It becomes more noticeable at low pressure. The upper pair of curves, which assume a feed pressure of 15 bar, show that the target can be $1.5 \%$ to $3 \%$ higher when a 2.0 -bar $\Delta P$ is imposed. The reason why the heating 
target increases is because the decrease in local pressure is larger for the fluid being cooled in the center of the bayonet than for the fluid being heated in the annulus. That means the temperature at which the product begins to condense decreases more than the temperature at which the acid completely vaporizes. Consequently, the opportunity for recuperation is reduced somewhat, resulting in a higher heating target. The effect is more noticeable at lower pressure because the relative changes are larger.

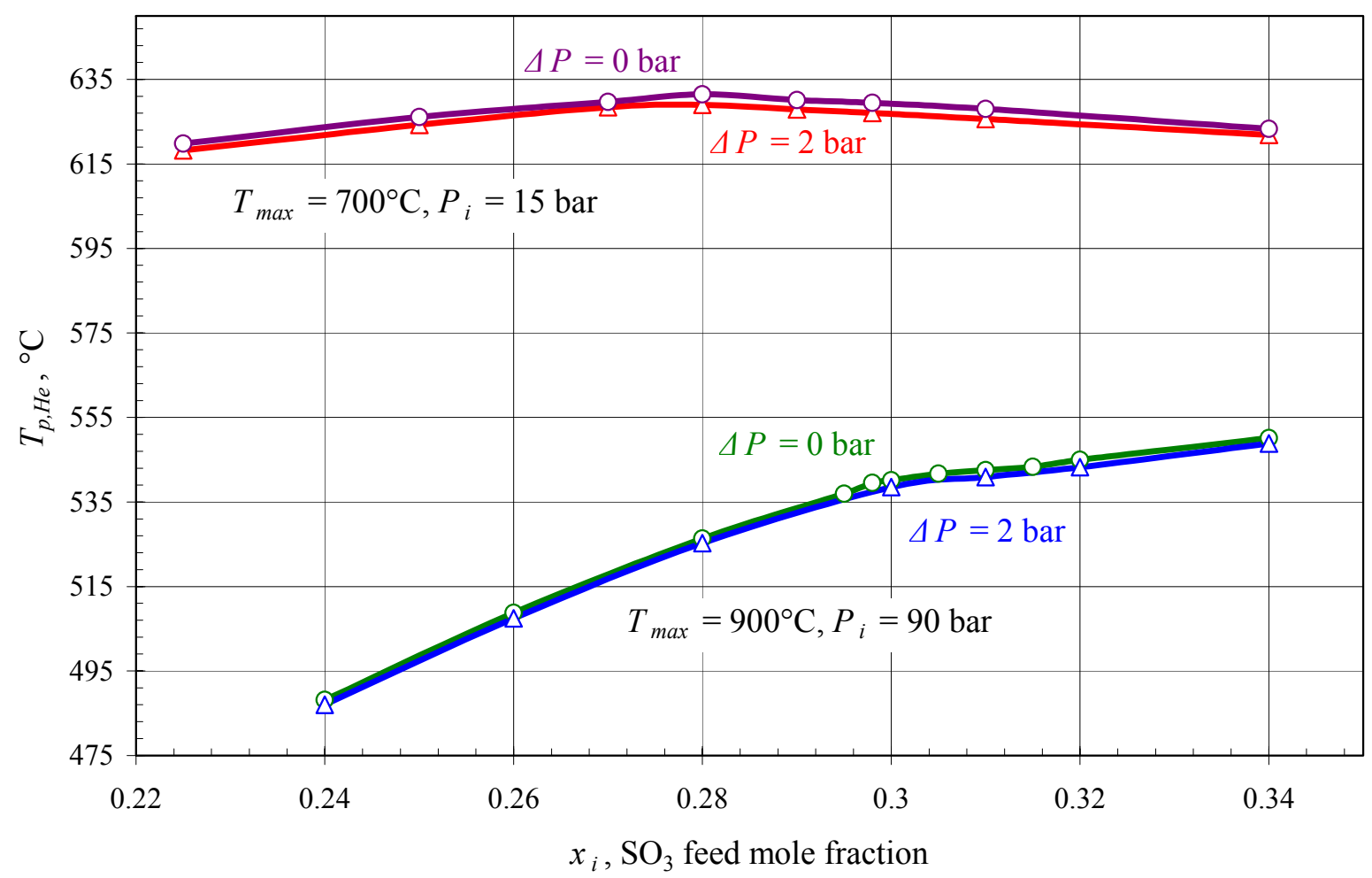

Figure 15. A plot of the $T_{p, H e}$ values versus $x_{i}$ values, at the stated $T_{\max }$ and $P_{i}$ combinations, with $\Delta P=0$ or 2 bar $\left(T_{i}=25^{\circ} \mathrm{C}, T_{\text {cat }}=675^{\circ} \mathrm{C},-\Delta T_{\text {eq }}=0\right.$, and $\left.\Delta T_{\text {min, recup }}=10^{\circ} \mathrm{C}\right)$; if $\Delta P=2$ bar, then $\Delta P_{p h b x}=0.5, \Delta P_{\text {spht }}=0.1, \Delta P_{\text {cat }}=1.0, \Delta P_{\text {cool }}=0.1$, and $\Delta P_{c n d x}=0.3 \mathrm{bar}$, else all $\Delta P \mathrm{~s}=0$.

As for the helium heat source pinch temperature (Figure 15), the effect of an imposed pressure drop is minimal, resulting only in a slight decrease (less than 1\%), which can be due to 
one of two factors. Conversion increases slightly because of the slightly lower catalyst bed outlet pressure. An increase in conversion will reduce the total amount of heat required in the catalyst bed, thereby lowering the helium pinch temperature in those cases where the catalyst bed inlet temperature is the limiting factor, as in Figure 13. The pinch temperature for recuperation decreases due to a lowering of the temperature at which the product begins to condense. This lowers the heating utility pinch temperature in those cases where the pinch temperature for recuperation is the limiting factor, as in Figure 4. In either case, the effect is a minor one.

\section{Discussion}

The pinch analysis of the bayonet reactor presented above allows an assessment of its performance potential without first having to perform a rigorous heat and mass transfer analysis. A detailed heat and mass transfer design will still be required before a recuperative bayonet sulfuric acid decomposition reactor can actually be built and operated near its theoretical optimum. That is beyond the scope of this study. However, with that caveat in mind, a number of observations can be made concerning the ability of this concept to be successfully implemented in a sulfur cycle flowsheet that can be competitive with conventional alkaline electrolysis.

The operating conditions that would give the lowest possible heating target are at the highest possible catalyst bed outlet temperature $\left(800^{\circ} \mathrm{C}\right.$ or higher $)$, the highest possible feed pressure (up to 90 bar), and use a feed containing around $30 \mathrm{~mol} \% \mathrm{SO}_{3}\left(42.9 \mathrm{~mol} \% \mathrm{H}_{2} \mathrm{SO}_{4}\right)$. Since the pinch point generally occurs where the annular fluid is boiling and the center-tube fluid is condensing, resulting in large heat transfer coefficients, it is reasonable to assume that the

minimum temperature difference for recuperation can be as low as $10^{\circ} \mathrm{C}$. If the catalyst can allow the decomposition reaction to proceed to equilibrium, then the lowest possible heat requirement will be achieved. 
Sulfuric acid produced in the Bunsen reaction step of the SI cycle is about $20 \mathrm{~mol} \%$ $\mathrm{H}_{2} \mathrm{SO}_{4}\left(57.6 \mathrm{wt} \% \mathrm{H}_{2} \mathrm{SO}_{4}\right.$ or $\left.16.7 \mathrm{~mol} \% \mathrm{SO}_{3}\right),{ }^{3}$ while the $\mathrm{SO}_{2}$-depolarized electrolysis step of the HyS cycle may be limited to an acid product concentration of about $50 \mathrm{wt} \% \mathrm{H}_{2} \mathrm{SO}_{4}(15.5 \mathrm{~mol} \%$ $\mathrm{H}_{2} \mathrm{SO}_{4}$ or $\left.13.4 \mathrm{~mol} \% \mathrm{SO}_{3}\right)^{7}$ if proton exchange membrane (PEM) technology is used. That means an acid concentration step will be inevitable if the bayonet is to be operated near its optimum. About two-thirds (SI cycle) to three-quarters (HyS PEM electrolyzer) of the water $\left(\mathrm{H}_{2} \mathrm{SO}_{4}\right.$ composition basis) will have to be removed from the sulfuric acid before it can be fed to the bayonet. This will require the expenditure of additional energy, most likely in the form of lowtemperature heat that will need to be included with the minimum heating target when benchmarking against the $450-\mathrm{kJ} / \mathrm{mol} \mathrm{SO}_{2}$ upper limit.

Some of the heat needed to concentrate the acid feed to the bayonet could, conceivably, be recovered from the product stream. At the optimum operating point, where the minimum heating target is $320.9 \mathrm{~kJ} / \mathrm{mol} \mathrm{SO}_{2}$, the minimum cooling target, $Q_{C, \min }$, is $94.5 \mathrm{~kJ} / \mathrm{mol} \mathrm{SO}_{2}$. That represents the heat content of the product stream between its outlet temperature and the temperature of the feed stream. For a feed stream temperature of $25^{\circ} \mathrm{C}$, the outlet temperature would be $192.4^{\circ} \mathrm{C}$. If the feed stream temperature were increased, the product stream temperature would increase by a corresponding amount, subject to the $94.5 \mathrm{~kJ} / \mathrm{mol} \mathrm{SO}_{2}$ enthalpy difference. This heat could be used to help drive the acid concentration step.

If the acid feed concentration is less than that which minimizes the heating target, then most of the increase in the high-temperature heat requirement will go into raising the cooling target. This is clearly illustrated in Figure 16. As the acid concentration is decreased below the optimum value of 0.298 , the increase in the minimum heating target is nearly matched by a 
corresponding increase in the minimum cooling target. The changes don't match exactly due to differences in feed conversion that lead to difference in flow rate and composition.

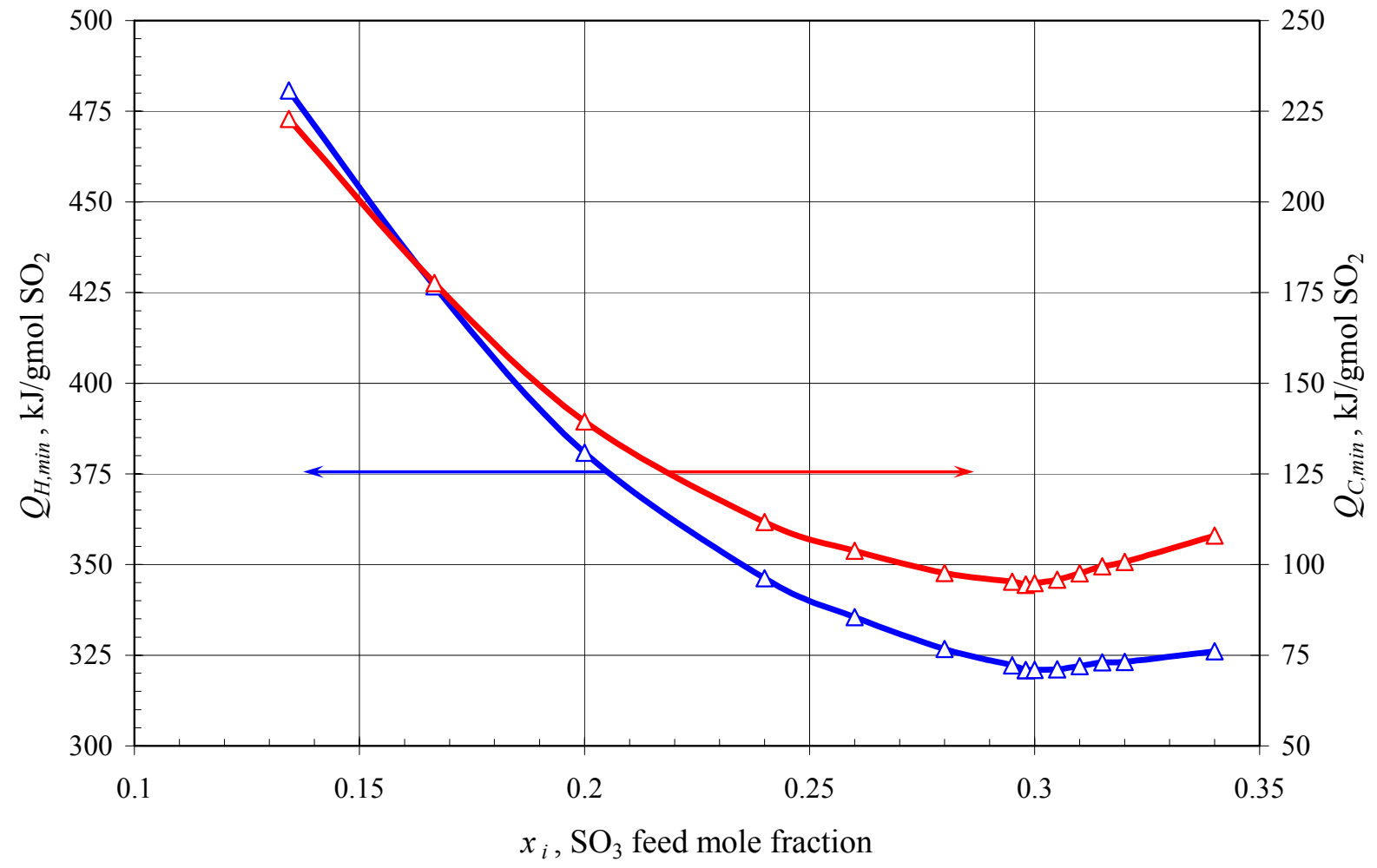

Figure 16. A plot of the minimum heating target (blue curve, 1.h.s. ordinate axis) and the minimum cooling target (red curve, r.h.s. ordinate axis) versus $\mathrm{SO}_{3}$ feed mole fraction at $T_{\max }=$ $900^{\circ} \mathrm{C}, P_{i}=90$ bar, $T_{i}=25^{\circ} \mathrm{C}, T_{c a t}=675^{\circ} \mathrm{C},-\Delta T_{e q}=0$, and $\Delta T_{\text {min, } \text {,ecup }}=10^{\circ} \mathrm{C}$

This suggests the possibility of a design trade-off. Lowering the mole fraction of the acid feed to the bayonet from the apparent optimum will increase the heating target while decreasing the magnitude of the separation task required, lowering the heat input needed for the concentration step. It will also increase the minimum cooling target, making it possible for more of the heat needed for the concentration step to be recovered from the bayonet product. Consequently, the true optimum feed concentration is the one that will balance the high- 
temperature energy needs of the bayonet decomposer with the lower-temperature energy needs of the acid concentration step, giving the best overall energy utilization. This can only be determined at the flowsheet level.

In fact, achieving the lowest possible value of the minimum heating target for the bayonet will not guarantee optimal operation of the sulfur cycle. For example, the cell potential in the electrolysis step of the HyS cycle increases with sulfuric acid concentration. ${ }^{19}$ Consequently, it is likely that the most efficient operating point for the process will not coincide with the most efficient operating point for the bayonet, but will be a compromise between competing demands throughout the flowsheet. Optimization of the overall process, rather than optimization of the bayonet, will be the overriding concern when designing the sulfur cycle flowsheet.

Nothing has been said thus far about the uncertainty of the thermodynamic model used in the Aspen Plus simulation. Looking at the results, it is clear that recuperation is limited by the boiling and condensing behavior of sulfuric acid at elevated pressures, since all the pinch points occur in the boiling region of the heating curve and the condensing region of the cooling curve. While the product also contains $\mathrm{SO}_{2}$ and $\mathrm{O}_{2}$, the pinch temperatures are well above the critical point for both $\mathrm{SO}_{2}$ and $\mathrm{O}_{2}$, so their solubilities in the condensate are small and have a negligible effect at the pinch. The relevant question is, then, how well do the thermodynamic models fit the known high-temperature vapor-liquid equilibrium behavior of sulfuric acid?

The high-temperature model used in this work assumes sulfuric acid dissociates in water to form ion pair complexes rather than positively and negatively charged ions. It treats the postulated ion pair complex as a molecular component with a very low boiling point, so there are no electrolytes. The equilibrium constant for dissociation as well as binary interaction parameters between the ion pair complex and water and sulfuric acid were fitted to high-temperature sulfuric 
acid vapor pressure data. ${ }^{20}$ As shown elsewhere ${ }^{7,21}$, the model not only fits these data very well, but also the upper temperature range of the well-known correlation by Gmitro and Vermeulen ${ }^{22}$ and can be considered reliable. Consequently, the uncertainty of the underlying thermodynamics is not a major concern and should not have a significant effect on the conclusions.

One interesting feature of the bayonet reactor is that concentrating the acid feed beyond $30 \mathrm{~mol} \% \mathrm{SO}_{3}\left(43 \mathrm{~mol} \% \mathrm{H}_{2} \mathrm{SO}_{4}\right)$ provides no benefit - in fact, it actually appears to increase the minimum heating target slightly. This suggests that the composition that provides the best opportunity for internal recuperation is about $30 \mathrm{~mol} \% \mathrm{SO}_{3}$, or $80.3 \mathrm{wt} \% \mathrm{H}_{2} \mathrm{SO}_{4}$.

The sulfuric acid decomposition reaction is an equilibrium-limited process. As such, the conversion of $\mathrm{H}_{2} \mathrm{SO}_{4}$ to $\mathrm{H}_{2} \mathrm{O}, \mathrm{SO}_{2}$, and $\mathrm{O}_{2}$ will be limited to around $50 \%$ when the heating target is at its minimum. That means roughly twice as much acid will need to be fed as consumed, and the unconverted acid will need to be recycled. The recycle will be more dilute than the feed, since it will capture most of the water released by the decomposition reaction. That implies a recycle concentration task that will require some energy input.

Taking all of these considerations into account, it appears that the minimum heating target for the bayonet reactor should be low enough to be successfully incorporated in a sulfur cycle process that would be competitive with conventional electrolysis while leaving sufficient allowance for the additional heat that will be needed to concentrate the feed. (One published flowsheet based on the bayonet concept requires a little less than $80 \mathrm{~kJ} / \mathrm{mol} \mathrm{SO}_{2}$ supplemental low-temperature heat for a $50-\mathrm{wt} \% \mathrm{H}_{2} \mathrm{SO}_{4}$ feed. ${ }^{7}$ )

The heat source temperature is an important factor in determining the practicality of the bayonet concept. From Figure 9, it should be clear that if the peak process fluid temperature is less than $750^{\circ} \mathrm{C}$ (reactor outlet temperature less than $825^{\circ} \mathrm{C}$ ), the minimum heating target will be 
too high for the resulting flowsheet to be competitive with alkaline electrolysis. Compounding this problem, the helium pinch temperature, $T_{p, H e}$, increases as the heat source temperature is decreased, implying that a smaller fraction of the reactor heat output can actually be applied toward decomposition. The bayonet reactor concept for sulfuric acid decomposition is practical only if the advanced nuclear heat source has a reactor outlet temperature of at least $825^{\circ} \mathrm{C}$. Reactor outlet temperatures below $825^{\circ} \mathrm{C}$ are too low for a practical process based on the bayonet decomposition reactor to achieve the desired thermal efficiency.

Finally, the apparent optimum feed concentration near $30 \mathrm{~mol} \% \mathrm{H}_{2} \mathrm{SO}_{4}\left(80 \mathrm{wt} \% \mathrm{H}_{2} \mathrm{SO}_{4}\right)$ suggests a development target for the sulfuric acid-producing step of the sulfur cycles. For example, if a $\mathrm{PEM} \mathrm{SO}_{2}$-depolarized electrolyzer capable of producing sulfuric acid containing $\geq$ $65 \mathrm{wt} \% \mathrm{H}_{2} \mathrm{SO}_{4}$ could be developed, it might be possible to concentrate the feed close to its optimum using only heat recovered from the bayonet effluent. Depending on the electrolyzer cell potential, that could lead to a very efficient HyS process. This should be an important consideration in any optimization of the Bunsen reaction for the SI cycle as well.

\section{Conclusions}

A pinch analysis of the hot helium-heated recuperative bayonet reactor concept for the high-temperature sulfuric acid decomposition step of the HyS and SI cycles was prepared. This analysis was used in conjunction with a statistical method to explore the likely operating range of the bayonet reactor and establish its limiting operating envelope.

Results indicate that the lowest value of the minimum heating target will be obtained at the highest process temperature and pressure considered $\left(900^{\circ} \mathrm{C}\right.$ and 90 bar) and with a sulfuric acid feed containing $29.8 \mathrm{~mol}_{0} \mathrm{SO}_{3}\left(80.1 \mathrm{wt} \% \mathrm{H}_{2} \mathrm{SO}_{4}\right)$. This implies a nuclear heat source outlet temperature of $975^{\circ} \mathrm{C}$ and a secondary heat transfer loop supply temperature of $925^{\circ} \mathrm{C}$. At these 
conditions, the minimum heating target was $320.9 \mathrm{~kJ} / \mathrm{mol} \mathrm{SO}_{2}$, assuming a catalyst bed inlet temperature of $675^{\circ} \mathrm{C}$, attainment of the decomposition equilibrium within the catalyst bed, and minimum temperature differences of $10^{\circ} \mathrm{C}$ for recuperation and $25^{\circ} \mathrm{C}$ for helium-to-process heat transfer. This is low enough for a practical sulfur cycle using conventional alkaline electrolysis as the benchmark.

There is some flexibility in operating conditions. Raising the feed temperature increases the outlet temperature but does not affect recuperation, provided the feed is below the pinch temperature. Lowering the feed concentration increases the minimum heating target, but most of the additional heat can be recovered by external recuperation from the product stream. Above a peak process temperature of $800^{\circ} \mathrm{C}$, raising the pressure lowers the heating target.

The peak process temperature, and consequently the reactor heat source outlet temperature, could be decreased by perhaps as much as $150^{\circ} \mathrm{C}$ while still allowing the overall sulfur cycle to remain competitive with water electrolysis. However, reducing the temperature by this amount (to a reactor outlet temperature of $825^{\circ} \mathrm{C}$ ) increases the minimum heating target to the point where the energy efficiency advantage over alkaline electrolysis is minimal. Lowering the operating temperature also increases the helium pinch temperature, so that only a fraction of the heat available from the nuclear heat source can be used within the bayonet.

The bayonet design is not practical for use with reactor outlet temperatures below $825^{\circ} \mathrm{C}$. Under these conditions, the combined effects of increases in the helium pinch temperature and in the minimum heating target would make the overall sulfur cycle too inefficient to be competitive with alkaline electrolysis.

\section{Acknowledgments}


This work was performed under US Department of Energy (DOE) Contract No. DE-A C09-08SR22470. Funding was provided by the DOE Office of Nuclear Energy (DOE-NE) under the Nuclear Hydrogen Initiative (NHI) program. Mr. Carl Sink was NHI program manager and Dr. Stephen Kung was program manager for thermochemical cycles. This work was part of the HyS cycle process development effort at Savannah River National Laboratory for which Dr.

William A. Summers was Principal Investigator.

\section{Nomenclature}

$\mathrm{BWR}=$ boiling water reactor

$\mathrm{GCC}=$ grand composite curve

$\mathrm{JMP}=$ statistical analysis software available from SAS Institute, Inc., Cary, NC.

LHD $=$ Latin hypercube design

LHV $=$ lower heating value $(242 \mathrm{~kJ} / \mathrm{mol}$ for hydrogen $)$

$\mathrm{PWR}=$ pressurized water reactor

$P_{i}=$ feed stream pressure, bar

$Q_{C, \text { min }}=$ minimum cooling target, $\mathrm{kJ} / \mathrm{mol} \mathrm{SO}_{2}$

$Q_{H, \min }=$ minimum heating target, $\mathrm{kJ} / \mathrm{mol} \mathrm{SO}_{2}$

$q_{H, 90}=$ ratio of minimum heating target at specified conditions to minimum heating target at 90 bar feed pressure, all other control variables held constant

$Q_{R, \max }=$ maximum recuperative interchange target, $\mathrm{kJ} / \mathrm{mol} \mathrm{SO}_{2}$

$q_{R, 90}=$ ratio of maximum recuperative interchange target at specified conditions to minimum heating target at 90 bar feed pressure, all other control variables held constant $T_{\text {cat }}=$ catalyst bed inlet temperature, ${ }^{\circ} \mathrm{C}$ 
$T_{i}=$ feed stream temperature, ${ }^{\circ} \mathrm{C}$

$T_{\max }=$ catalyst bed outlet/maximum process fluid temperature, ${ }^{\circ} \mathrm{C}$

$T_{p, H e}=$ helium heat source pinch temperature, ${ }^{\circ} \mathrm{C}$

$x_{i}=$ mole fraction $\mathrm{SO}_{3}$ in feed stream

Greek Letters

$\Delta P=$ total pressure drop across bayonet reactor, bar

$\Delta P_{c a t}=$ pressure drop across bayonet reactor catalyst bed, bar

$\Delta P_{c n d x}=$ pressure drop across bayonet reactor partial condensing zone, bar

$\Delta P_{\text {cool }}=$ pressure drop across bayonet reactor cooling zone, bar

$\Delta P_{p h b x}=$ pressure drop across bayonet reactor preheating and boiling zone, bar

$\Delta P_{\text {spht }}=$ pressure drop across bayonet reactor vapor superheating zone, bar

$\Delta T_{e q}=$ temperature approach to equilibrium for catalytic $\mathrm{SO}_{3}$ decomposition reaction, ${ }^{\circ} \mathrm{C}$

$\Delta T_{\min , \mathrm{He}}=$ minimum temperature difference for helium-to-process fluid heat transfer, ${ }^{\circ} \mathrm{C}$

$\Delta T_{\text {min, recup }}=$ minimum temperature difference for recuperative heat transfer, ${ }^{\circ} \mathrm{C}$

$X=$ fractional conversion of $\mathrm{SO}_{3}$ to $\mathrm{SO}_{2}$

$\chi_{90}=$ ratio of $\mathrm{SO}_{3}$ fractional conversion at specified conditions to fractional conversion at 90 bar feed pressure, all other control variables held constant

\section{Literature Cited}


(1) Raman, V. Hydrogen Production and Supply Infrastructure for Transportation - Discussion Paper. Final Proceedings of the Pew Center/NCEP Workshop on The 10-50 Solution:

Technologies and Policies for a Low-Carbon Future. Washington, DC. March 25-26, 2004. available at http://www.pewclimate.org/docUploads/10-50 Full\%20Proceedings.pdf. accessed December 8, 2008.

(2) The Hydrogen Economy: Opportunities, Costs, Barriers, and R\&D Needs. Washington, DC: National Academy of Engineering, 2004.

(3) Norman, J.H.; Russell, J.L., Jr.; Porter, J.T., II; McCorkle, K.H.; Roemer, T.S.; Sharp, R. Process for the Thermochemical Production of Hydrogen. General Atomic Co., US Patent No. 4089940, 1978.

(4) Brecher, L.E.; Wu, C.K. Electrolytic decomposition of water. Westinghouse Electric Corp., US Patent No. 3888750, 1975.

(5) Ginosar, D.M.; Rollins, H.W.; Petkovic, L.M.; Burch, K.C.; Rush, M.J. High-temperature sulfuric acid decomposition over complex metal oxide catalysts. Int. J. Hydrogen Energy 2009, 34(9), 4065-4073.

(6) Gelbard, F.; Moore, R.; Parma, E. Status of Initial Testing of the $\mathrm{H}_{2} \mathrm{SO}_{4}$ Section of the ILS Experiment. Sandia National Laboratories Report SAND2007-7841, December 2007. available at http://www.prod.sandia.gov/cgi-bin/techlib/access-control.pl/2007/077841.pdf. accessed February 23, 2009.

(7) Gorensek, M.B.; Summers, W.A. Hybrid Sulfur flowsheets using PEM electrolysis and a bayonet decomposition reactor. Int. J. Hydrogen Energy 2009, 34(9), 4097-4114.

(8) Goldstein, S.; Borgard, J.-M.; Vitart, X. Upper bound and best estimate of the efficiency of the iodine sulphur cycle. Int. J. Hydrogen Energy 2005, 30(6), 619-626.

(9) Öztürk, I.T.; Hammache, A.; Bilgen, E. An Improved Process for $\mathrm{H}_{2} \mathrm{SO}_{4}$ Decomposition Step of the Sulfur-Iodine Cycle. Energy Convers., Mgmt. 1995, 36(1), 11-21.

(10) Review of DOE'S Nuclear Energy Research and Development Program. Washington, DC: National Research Council, 2008.

(11) Pickard, P.S. personal communication, December 18, 2008.

(12) Nagarajan, V.; Ponyavin V.; Chen Y.; Vernon, M.E.; Pickard, P.; Hechanova, A.E.

Numerical study of sulfur trioxide decomposition in bayonet type heat exchanger and chemical decomposer with porous media zone and different packed bed designs. Int. J. Hydrogen Energy 2008, 33(22), 6445-6455.

(13) Aspen Plus Version 7.0 (22.0.4191), Aspen Technology, Inc.: Burlington, MA, 1981-2008.

(14) Aspen Energy Analyzer Version 7.0 (22.0.0.5705), Aspen Technology, Inc.: Burlington,

MA, 1995-2008.

(15) Linhoff, B. et al. User Guide on Process Integration for the Efficient Use of Energy, Revised First Edition; Institution of Chemical Engineers: Rugby, Warwickshire, UK, 1994.

(16) Santner, T.J.; Williams, B.J.; Notz, W.I; The Design and Analysis of Computer Experiments; Springer: New York, 2003.

(17) JMP Version 7.0.2, SAS Institute, Inc.: Cary, NC, 1989-2007.

(18) Brown, L.C.; Besenbruch, G.E.; Lentsch, R.D.; Schultz, K.R.; Funk, J.F.; Pickard, P.S.; Marshall, A.C.; Showalter, S.K. High efficiency generation of hydrogen fuels using nuclear power. Final technical report for the period August 1, 1999 through September 30, 2002, from General Atomics Corp. to US DOE, GA-A24285, Jun 2003. 
(19) Gorensek, M.B.; Staser, J.A.; Stanford, T.G.; Weidner J.W. A Thermodynamic Analysis of the $\mathrm{SO}_{2} / \mathrm{H}_{2} \mathrm{SO}_{4}$ System in $\mathrm{SO}_{2}$-depolarized Electrolysis. Int. J. Hydrogen Energy doi:10.1016/j.ijhydene.2009.06.020.

(20)Wüster, G. p, v, T-und Dampfdruckmessungen zur Bestimmung Thermodynamischer Eigenschaften Starker Elektrolyte bei Erhöhtem Druck, Doctoral dissertation, RWTH-Aachen; 1979.

(21) Mathias, P.M. Modeling the sulfur-iodine cycle: Aspen Plus building blocks and simulation models. Final report from Aspen Technology, Inc. to General Atomics and Sandia National Laboratories, Oct 24, 2002.

(22) Gmitro, J.I.; Vermeulen, T. Vapor-liquid equilibrium for aqueous sulfuric acid. AIChE $J$ 1964, 10,740 . 